\title{
Extended Abstracts
}

Neonatology

\section{1}

\section{Women Are Designed to Deliver Vaginally and Not by Cesarean Section: An Obstetrician's View}

G.H.A. Visser

Department of Obstetrics, University Medical Center, Utrecht, The Netherlands

Worldwide, there is a rapid increase in deliveries by cesarean section. The large differences among countries, from about 16 to more than $60 \%$, suggest that the cesarean delivery (CD) rate has little to do with evidence-based medicine. In this review, the background for the increasing CD rate is discussed, as well as the limited positive effects on neonatal outcome, in both term and preterm neonates. Negative effects of $\mathrm{CD}$, including direct maternal morbidity, complicated subsequent pregnancies and iatrogenic early delivery resulting in increased neonatal morbidity, are discussed in addition to long-term implications for the offspring involving altered development of the immune system. The 'battle' to lower the CD rate will be difficult, but we should not forget that women are designed to deliver vaginally and not by cesarean section.

The complete review will be published in Neonatology, vol. 107, no. 1, 2015.

\section{2}

Stabilization of Very Immature Preterm Infants in the Delivery Room: Pitfalls and Promising Strategies

\section{C.J. Morley}

Retired Professor of Neonatal Medicine, Department of Obstetrics and Gynaecology, University of Melbourne, Vic., Australia; Honorary Lecturer, Department of Obstetrics and Gynaecology, University of Cambridge, UK

In 2003, at the Royal Women's Hospital in Melbourne, we started investigating neonatal resuscitation by recording videos and signals of inspiratory and expiratory gas flow, tidal volumes, mask or endotracheal gas leak, inflation pressures and times, spontaneous breathing patterns, oxygen saturation $\left(\mathrm{SpO}_{2}\right)$, heart rate and expired carbon dioxide $[1,2]$. We realised there were aspects that we could not investigate in babies and so worked with the Prof. Hooper at Monash University, Melbourne, studying fetal and neonatal lambs and rabbits $[3,4]$. We realised full resuscitation is very rare in babies and what we do is help them transition from in utero to ex utero breathing. We suggest it is more appropriate to call this stabilisation [5]. What We Learned: Intermittent counting of heart rate is inaccurate. Dynamic, heart rate and $\mathrm{SpO}_{2}$ changes can be obtained by about $90 \mathrm{~s}$ after birth with an oximeter probe applied to the right wrist [6]. Seeing changes in heart rate rather than heart rate every $30 \mathrm{~s}$ is the best early guide to the success of any resuscitation. At $1 \mathrm{~min}$, a heart rate $<100 / \mathrm{min}$ occurs in about half of healthy babies and so is not a good indication of asphyxia, as long as the baby has good tone [7]. Most bradycardia and hypotension, immediately after birth, is due to vagal stimulation, probably due to clamping of the umbilical cord too early after birth [8].

\section{KARGER}

E-Mail karger@karger.com

www.karger.com/neo
(C) 2014 S. Karger AG, Basel

1661-7800/14/1063-0261\$39.50/0 
There is no evidence for using 30 or $60 \mathrm{~s}$ after birth to decide when to start ventilation. Most people take longer than this just assessing the baby [9]. Birth is a stressful time and babies often need longer to recover and start breathing. Facemask ventilation is difficult, with a large leak often being a serious problem even for experienced neonatologists [10]. Unfortunately, it is difficult to assess the degree of leak. There is no facemask that is leak free. It is how they are positioned and held on the face that is important. Mask hold and positioning techniques are best taught with a leak-free manikin and a respiratory monitor [11]. It has been suggested it does not matter if there is a mask leak because the resuscitators can see the effect of ventilation from chest rise and heart rate. Unfortunately, this is not accurate [12]. With a variable mask leak, it is likely that either inadequate tidal volume is delivered or is very large and potentially damaging. From recordings of mask ventilation, airway obstruction is common even though appropriate inflating pressure is used [13]. Causes of the obstruction have not been elucidated. The only way to know how much leak is occurring, whether there is airway obstruction and the amount of tidal volume delivered, is by using a flow sensor and display of flow and tidal volume [14]. It has been suggested that very preterm babies must be ventilated from birth because they do not breathe. However, the majority will start to breath or crying after birth [2]. They need help with continuous positive airway pressure (CPAP) or positive end-expiratory pressure (PEEP) to aerate their lungs [15]. Inspired oxygen is toxic for neonates and should not be used unless really needed [16]. It is difficult to judge cyanosis accurately [1]. In all babies, $\mathrm{SpO}_{2}$ is about $60 \%$ just after birth and can take about 10 min to reach the mid 90s. Graphs of the normal changes in $\mathrm{SpO}_{2}$ after birth have been produced and should be used to help decide whether the fraction of inspired oxygen $\left(\mathrm{FiO}_{2}\right)$ should be changed $[7,17]$. Probably, it is best to start with air and only increase $\mathrm{FiO}_{2}$ if it is needed. The main reason a newly born baby has a low $\mathrm{SpO}_{2}$ is that the lungs are unaerated and full of fluid. Before gas exchange can take place, this fluid needs to be cleared. In weak preterm or compromised infants, this is best aided with PEEP immediately after birth to assist the formation and maintenance of a functional residual capacity. Before oxygen is considered in apnoeic infants, lung aeration should be facilitated with PEEP and probably a prolonged inflation for at least $20 \mathrm{~s}$ with a peak inspiratory pressure of $30 \mathrm{~cm} \mathrm{H}_{2} \mathrm{O}$. CPAP, PEEP and sustained inflations can only be given with a T-piece device. About $50 \%$ of very preterm infants can be managed with CPAP and do not need intubation and surfactant [18]. Despite guidelines suggesting neonatologists should judge the viability in very preterm infants immediately after birth to help decide on resuscitation, their judgment is imprecise [19]. It is not possible to pick the winners and losers by observation. There are times when, with apparently appropriate tidal volumes, a baby does not respond to ventilation. Measuring whether expired $\mathrm{CO}_{2}$ is detected helps assess whether ventilation is occurring [20]. In summary, to improve and understand neonatal resuscitation it should be guided by monitoring and displaying relevant physiological signals.

\section{References}

1 O'Donnell CP, Kamlin CO, Davis PG, et al: Clinical assessment of infant colour at delivery. Arch Dis Child Fetal Neonatal Ed 2007;92:F465-F467.

-2 O’Donnell CP, Kamlin CO, Davis PG, Morley CJ: Crying and breathing by extremely preterm infants immediately after birth. J Pediatr 2010;156: 846-847.
3 Hooper SB, Kitchen MJ, Wallace MJ, et al: Imaging lung aeration and lung liquid clearance at birth. FASEB J 2007;21:3329-3337.

$\checkmark 4$ Probyn ME, Hooper SB, Dargaville PA, et al: Positive end expiratory pressure during resuscitation of premature lambs rapidly improves blood gases without adversely affecting arterial pressure. Pediatric Res 2004;56:198-204.

5 Morley CJ, Davis PG: Advances in neonatal resuscitation: supporting transition. Arch Dis Child Fetal Neonatal Ed 2008;93:F334-F336.

6 O'Donnell CP, Kamlin CO, Davis PG, Morley CJ: Feasibility of and delay in obtaining pulse oximetry during neonatal resuscitation. J Pediatr 2005; 147:698-699.

7 Dawson JA, Kamlin CO, Wong C, et al: Changes in heart rate in the first minutes after birth. Arch Dis Child Fetal Neonatal Ed 2010;95:F177F181.

8 Bhatt S, Alison BJ, Wallace EM, et al: Delaying cord clamping until ventilation onset improves cardiovascular function at birth in preterm lambs. J Physiol 2013;591:2113-2126.

-9 McCarthy LK, Morley CJ, Davis PG, et al: Timing of interventions in the delivery room: does reality compare with neonatal resuscitation guidelines? J Pediatr 2013;163:1553.e1-1557.e1.

10 Wood FE, Morley CJ, Dawson JA, et al: Assessing the effectiveness of two round neonatal resuscitation masks: study 1. Arch Dis Child Fetal Neonatal Ed 2008;93:F235-F237.

11 Wood FE, Morley CJ, Dawson JA, Davis PG: A respiratory function monitor improves mask ventilation. Arch Dis Child Fetal Neonatal Ed 2008;93:F380-F381.

12 Poulton DA, Schmolzer GM, Morley CJ, Davis PG: Assessment of chest rise during mask ventilation of preterm infants in the delivery room. Resuscitation 2010;82:175-179.

13 Schmolzer GM, Dawson JA, Kamlin CO, et al: Airway obstruction and gas leak during mask ventilation of preterm infants in the delivery room. Arch Dis Child Fetal Neonatal Ed 2011;96:F254-F257.

14 Schmolzer GM, Kamlin OC, Dawson JA, et al: Respiratory monitoring of neonatal resuscitation. Arch Dis Child Fetal Neonatal Ed 2010; 95:F295-F303.

15 Siew ML, Te Pas AB, Wallace MJ, et al: Positive end-expiratory pressure enhances development of a functional residual capacity in preterm rabbits ventilated from birth. J Appl Physiol 2009;106:1487-1493.

16 Saugstad OD: Resuscitation with pure oxygen at birth: it is time for a change. J Matern Fetal Neonatal Med 2004;15:73-74.

17 Dawson JA, Kamlin CO, Vento M, et al: Defining the reference range for oxygen saturation for infants after birth. Pediatrics 2010;125:e1340e1347.

18 Morley CJ, Davis PG, Doyle LW, et al: Nasal CPAP or intubation at birth for very preterm infants. N Engl J Med 2008;358:700-708.

19 Manley BJ, Dawson JA, Kamlin CO, et al: Clinical assessment of extremely premature infants in the delivery room is a poor predictor of survival. Pediatrics 2010;125:e559-e564.

20 Hooper SB, Fouras A, Siew ML, et al: Expired CO2 levels indicate degree of lung aeration at birth. PLoS One 2013;8:e70895.

\section{3}

\section{When and How to Give Surfactant?}

R.F. Soll

Department of Pediatrics, University of Vermont, Burlington, Vt., USA

Authoritative committees in the United States and in Europe have proposed recommendations and guidelines regarding the management of the respiratory distress syndrome (RDS) [1, 2]. These guidelines include specific evidence-based recommenda- 
tions regarding the use of surfactant, detailing which surfactant administration strategy, which surfactant product and which surfactant dosage might be optimal. In general, these guidelines reflect a clear evidence basis for the recommendations. However, as with all guidelines and recommendations, there are areas of controversy and there are areas of newly emerging research. Surfactant Strategy: Surfactant therapy, whether used in infants at risk of RDS (prophylaxis) or in infants with established RDS (rescue or selective treatment), is effective in reducing pneumothorax and mortality [3-6]. However, the preferred approach to treatment and the timing of treatment remains controversial. Clinical trials from the 1990s strongly supported the use of prophylactic surfactant and ongoing ventilator support in infants at high risk for RDS (typically defined as 30 weeks of gestation or less) as opposed to later treatment of these infants with worsening RDS. However, recent studies have suggested that in infants who have received a full course of antenatal steroids, stabilization on nasal continuous positive airway pressure (CPAP) immediately after delivery may be the superior approach [7]. If an infant is stabilized on CPAP, it is unclear whether that infant might benefit from surfactant therapy prior to developing frank signs and symptoms of respiratory insufficiency; likewise, it is unclear what the threshold for treatment should be. The European guidelines suggest that infants $<26$ weeks of gestation should receive surfactant treatment when the requirement for supplemental oxygen is $>30 \%$, and infants $>26$ weeks of gestation should receive surfactant when the requirement for supplemental oxygen is $>40 \%$. These seem reasonable cut points based on the available clinical data. In this situation, a variety of approaches to surfactant administration have been taken. The InSurE approach calls for intubation, intratracheal surfactant administration and rapid extubation to CPAP or nasal intermittent positive pressure ventilation immediately following surfactant administration [8]. Recent data have suggested that even less invasive approaches to surfactant treatment may be advantageous. Minimally invasive surfactant treatment using thin catheters and administering surfactant to spontaneously breathing infants on CPAP has been used in studies in Germany and Australia with promising early results $[9,10]$. Despite our best efforts to support infants less invasively, many infants will have worsening RDS and need further support. In intubated infants with RDS, the consensus guidelines state that a policy of early rather than late rescue surfactant is the optimal approach. Surfactant Products: Current guidelines recommend the use of animal-derived surfactant preparations. Multiple studies comparing animal-derived surfactant preparations to non-protein-containing synthetics support this recommendation [11]. The use of animal-derived products is associated with a decrease in pneumothorax and a decrease in mortality. Emerging research is evaluating synthetic surfactant preparations that include peptides or whole protein that, when added in an aqueous dispersion of phospholipids, function in a fashion similar to endogenous pulmonary surfactant protein. Two clinical trials suggest that these products may be as effective as animal-derived surfactant preparations $[12,13]$. It remains to be seen whether or not these products are superior or safer than the currently available animal-derived products. Surfactant Dosage: Evidence from animal models and clinical trials supports a minimum dose of $100 \mathrm{mg}$ phospholipid $/ \mathrm{kg}$. In trials comparing $100 \mathrm{mg}$ of poractant $\alpha$ or beractant to $200 \mathrm{mg}$ of poractant $\alpha$, the $200-\mathrm{mg}$ dose appears to lead to an improved clinical outcome [14]. However, few trials have compared dosages of similar surfactant products. In either case, infants who are intubated and have signs and symptoms of RDS should be given surfactant as soon as possible and infants who have persistent or relapsing disease $12 \mathrm{~h}$ after dosing should be considered for repeat dosing $[15,16]$. Conclusions: Research continues to optimize surfactant therapy, including the evaluation of less invasive surfactant administration and surfactant products containing synthetic proteins. It remains to be seen whether this research will lead to further improvements in our use of surfactant and clinical outcome in newborn infants.

\section{References}

1 Sweet DG, Carnielli V, Greisen G, Hallman M, Ozek E, Plavka R, Saugstad OD, Simeoni U, Speer CP, Vento M, Halliday HL; European Association of Perinatal Medicine: European consensus guidelines on the management of neonatal respiratory distress syndrome in preterm infants - 2013 update. Neonatology 2013;103:353-368.

2 Polin RA, Carlo WA; Committee on Fetus and Newborn; American Academy of Pediatrics: Surfactant replacement therapy for preterm and term neonates with respiratory distress. Pediatrics 2014;133:156-163.

- 3 Soll R, Ozek E: Prophylactic protein free synthetic surfactant for preventing morbidity and mortality in preterm infants. Cochrane Database Syst Rev 2010;1:CD001079.

4 Soll RF: Prophylactic natural surfactant extract for preventing morbidity and mortality in preterm infants. Cochrane Database Syst Rev 2000; 2:CD000511.

5 Soll RF: Synthetic surfactant for respiratory distress syndrome in preterm infants. Cochrane Database Syst Rev 2000;2:CD001149.

6 6 Seger N, Soll R: Animal derived surfactant extract for treatment of respiratory distress syndrome. Cochrane Database Syst Rev 2009;2:CD007836.

7 Rojas-Reyes MX, Morley CJ, Soll R: Prophylactic versus selective use of surfactant in preventing morbidity and mortality in preterm infants. Cochrane Database Syst Rev 2012;3:CD000510.

8 Stevens TP, Harrington EW, Blennow M, Soll RF: Early surfactant administration with brief ventilation vs. selective surfactant and continued mechanical ventilation for preterm infants with or at risk for respiratory distress syndrome. Cochrane Database Syst Rev 2007;4:CD003063.

-9 Göpel W, Kribs A, Ziegler A, Laux R, Hoehn T, Wieg C, Siegel J, Avenarius S, von der Wense A, Vochem M, Groneck P, Weller U, Möller J, Härtel C, Haller S, Roth B, Herting E; German Neonatal Network: Avoidance of mechanical ventilation by surfactant treatment of spontaneously breathing preterm infants (AMV): an open-label, randomised, controlled trial. Lancet 2011;378:1627-1634.

10 Dargaville PA, Aiyappan A, De Paoli AG, et al: Minimally-invasive surfactant therapy in preterm infants on continuous positive airway pressure. Arch Dis Child Fetal Neonatal Ed 2013;98:F122-F126.

-11 Soll RF, Blanco F: Natural surfactant extract versus synthetic surfactant for neonatal respiratory distress syndrome. Cochrane Database Syst Rev 2001;2:CD000144

12 Moya FR, Gadzinowski J, Bancalari E, Salinas V, Kopelman B, Bancalari A, Kornacka MK, Merritt TA, Segal R, Schaber CJ, Tsai H, Massaro J, d'Agostino R; International Surfaxin Collaborative Study Group: A multicenter, randomized, masked, comparison trial of lucinactant, colfosceril palmitate, and beractant for the prevention of respiratory distress syndrome among very preterm infants. Pediatrics 2005;115:1018-1029.

13 Sinha SK, Lacaze-Masmonteil T, Valls i Soler A, Wiswell TE, Gadzinowski J, Hajdu J, Bernstein G, Sanchez-Luna M, Segal R, Schaber CJ, Massaro J, d'Agostino R; Surfaxin Therapy against Respiratory Distress Syndrome Collaborative Group: A multicenter, randomized, controlled trial of lucinactant versus poractant alfa among very premature infants at high risk for respiratory distress syndrome. Pediatrics 2005;115:10301038.

14 Singh N, Hawley KL, Viswanathan K: Efficacy of porcine versus bovine surfactants for preterm newborns with respiratory distress syndrome: systematic review and meta-analysis. Pediatrics 2011;128:e1588-e1595. 
15 Bahadue FL, Soll R: Early versus delayed selective surfactant treatment for neonatal respiratory distress syndrome. Cochrane Database Syst Rev 2012;11:CD001456.

16 Soll R, Ozek E: Multiple versus single doses of exogenous surfactant for the prevention or treatment of neonatal respiratory distress syndrome. Cochrane Database Syst Rev 2009;1:CD000141.

\section{4 \\ How Much Oxygen Is Tolerable in the Delivery Room?}

\section{O.D. Saugstad}

Department of Pediatric Research, Division of Women and Child Health, Oslo University Hospital, University of Oslo, Oslo, Norway

Shortly after oxygen was discovered as an element in the 1770 s it was introduced in newborn care and resuscitation. When in 1861 and 1862 Little and Mitchell, respectively, described cerebral palsy as a consequence of birth asphyxia, oxygen was considered as a cornerstone in newborn resuscitation. In 1928, Flagg developed a device delivering pure oxygen with $\mathrm{CO}_{2}$ during newborn resuscitation [1]. In spite of the fact that it was understood in the 1950s that oxygen may be detrimental to premature infants, the common belief was that the brief exposure of pure oxygen during resuscitation after birth had no negative impact on the newborn [2]. The introduction of the Apgar score contributed further to an uncritical use of oxygen for newborn resuscitation. Virginia Apgar [3] herself used oxygen liberally. Color is one of the variables in the Apgar score, in order to become pink the first minutes of life oxygen must be delivered. Therefore, in many centers it became common practice to 'pink up' newborn babies by giving them oxygen immediately after birth in order to achieve a high Apgar score. Today, we know this may be detrimental and the Apgar scoring has probably done considerable harm to the world's newborn infants since its introduction 60 years ago. In 1980, we for the first time questioned the practice of giving high oxygen concentrations during resuscitation. The rationale was our new understanding that excess free radicals may be generated during posthypoxic reoxygenation [4]. A number of animal studies and 10 clinical studies published from 1993 to 2007 showed that it is feasible to start resuscitation with air instead of $100 \%$ oxygen. Further, accumulating data strongly indicated that hyperoxic reoxygenation might even be harmful [5]. Term Newborn Infants: Several meta-analyses have demonstrated the beneficial effect of starting resuscitation of term or near-term infants with air instead of $100 \%$ oxygen. In the latest meta-analysis including 10 studies with more than 2,000 babies [6], the relative risk for neonatal mortality of 0.69 (95\% CI $0.54-0.88$ ) was in favor of air. Thus, international guidelines were changed recommending to start resuscitation of term and near-term newborns with air instead of $100 \%$ oxygen when needing positive pressure ventilation at birth. In 2010, the International Liaison Committee on Resuscitation recommended: 'In term infants receiving resuscitation at birth with positive pressure ventilation, it is best to begin with air rather than $100 \%$ oxygen' [7]. The 2012 WHO guidelines stated: 'In newly-born term or preterm ( $>32$ weeks gestation) babies requiring positive-pressure ventilation, ventilation should be initiated with air' [8]. It has been estimated that the change in practice from pure oxygen to air may save around 250,000 newborn lives annually. Air substituting pure oxygen opens up for resuscitation in many areas where oxygen was not available. A recent study showed that $30 \%$ of fresh stillbirths may be rescued by air ventilation at birth, translating to approximately 300,000 additionally saved lives annually [9]. Thus, more than half a million newborn lives may be saved each year by air resuscitation. In the immediate postnatal period, it seems important to keep oxygen tension within normal values. Recently, a study by Kapadia et al. [10] demonstrated a lower incidence of severe and moderate hypoxic ischemic encephalopathy and less need for hypothermia treatment in asphyxiated newborns transferred from the delivery room to the intensive care unit with a physiologic versus a high $\mathrm{PaO}_{2}$. Preterm Infants: There has been uncertainty about how to oxygenate preterm infants $\leq 32$ weeks needing ventilation after birth. A few smaller studies testing out for instance 30 versus 90 or 21 versus $100 \%$ oxygen have been published [11-13]. Escrig et al. [11] and Vento et al. [12] have demonstrated that starting with 90 instead of $30 \%$ oxygen increases oxidative stress and markers of inflammation for several days. A recent meta-analysis and systematic review of 10 studies including 676 babies compared outcome of babies started with low $(0.21-0.30)$ or high inspired oxygen $\left(\mathrm{FiO}_{2}\right.$; $0.60-1.0)$. There was no significant difference in mortality although the relative risk was 0.62 in favor of low initial $\mathrm{FiO}_{2}$ (95\% CI 0.37 1.04) [14]. There were no differences regarding bronchopulmonary dysplasia or intraventricular hemorrhage. Based on these studies, it may be reasonable to start with a low $\mathrm{FiO}_{2}$ in babies $<33$ weeks in line with WHO recommendations: 'For preterm babies born at or before 32 weeks gestation, it is preferable to start ventilation with $30 \%$ rather than $100 \%$ oxygen. If this is not possible, ventilation should be started with air' [8]. Conclusion: Term newborn infants in need of ventilation at birth should be started with air instead of $100 \%$ oxygen. Their $\mathrm{PaO}_{2}$ should be kept at physiologic ranges after the resuscitation. Until further evidence, preterm infants $<33$ weeks could be started with a low $\mathrm{FiO}_{2}$, between 21 and $30 \%$ oxygen. In both term and preterm babies, $\mathrm{FiO}_{2}$ should preferably be adjusted during resuscitation to approach the normal development of saturation during the first $10 \mathrm{~min}$ of life [15].

\section{References}

1 Obladen M: History of neonatal resuscitation. Part 2: oxygen and other drugs. Neonatology 2009;95:91-96.

-2 Guidelines for cardiopulmonary resuscitation and emergency cardiac care. Emergency Cardiac Care Committee and Subcommittees, American Heart Association. Part VII. Neonatal resuscitation. JAMA 1992;268: 2276-2281.

- 3 Apgar V: A proposal for a new method of evaluation of the newborn infant. Curr Res Anesth Analg 1953;32:260-267.

4 Saugstad OD, Aasen AO: Plasma hypoxanthine concentrations in pigs. A prognostic aid in hypoxia. Eur Surg Res 1980;12:123-129.

5 Saugstad OD: Resuscitation of newborn infants: from oxygen to room air. Lancet 2010;376:1970-1971.

-6 Saugstad OD, Ramji S, Soll RF, Vento M: Resuscitation of newborn infants with 21 or $100 \%$ oxygen: an updated systematic review and metaanalysis. Neonatology 2008;94:176-182.

7 Perlman JM, Wyllie J, Kattwinkel J, Atkins DL, Chameides L, Goldsmith JP, Guinsburg R, Hazinski MF, Morley C, Richmond S, Simon WM, Singhal N, Szyld E, Tamura M, Velaphi S; Neonatal Resuscitation Chapter Collaborators: Part 11: neonatal resuscitation: 2010 International Consensus on Cardiopulmonary Resuscitation and Emergency Cardiovascular Care Science with Treatment Recommendations. Circulation 2010;122:S516-S538. 
8 WHO: Guidelines on Basic Newborn Resuscitation. Geneva, WHO, 2012.

-9 Carlo WA, Goudar SS, Jehan I, Chomba E, Tshefu A, Garces A, Parida S, Althabe F, McClure EM, Derman RJ, Goldenberg RL, Bose C, Krebs NF, Panigrahi P, Buekens P, Chakraborty H, Hartwell TD, Wright LL; First Breath Study Group: Newborn-care training and perinatal mortality in developing countries. N Engl J Med 2010;362:614-623.

10 Kapadia VS, Chalak LF, DuPont TL, et al: Perinatal asphyxia with hyperoxemia within the first hour of life is associated with moderate to severe hypoxic-ischemic encephalopathy. J Pediatr 2013;163:949-954.

11 Escrig R, Arruza L, Izquierdo I, et al: Achievement of targeted saturation values in extremely low gestational age neonates resuscitated with low or high oxygen concentrations: a prospective, randomized trial. Pediatrics 2008;121:875-881.

12 Vento M, Moro M, Escrig R, et al: Preterm resuscitation with low oxygen causes less oxidative stress, inflammation, and chronic lung disease. Pediatrics2009;124:e439-e449.

13 Wang CL, Anderson C, Leone TA, et al: Resuscitation of preterm neonates by using room air or 100\% oxygen. Pediatrics 2008;12:1083-1089.

14 Saugstad OD, Aune D, Aguar M, et al: Systematic review and meta-analysis of optimal initial fraction of oxygen levels in the delivery room at $\leq 32$ weeks. Acta Paediatr 2014;103:744-751.

15 Dawson JA, Kamlin CO, Vento M, et al: Defining the reference range for oxygen saturation for infants after birth. Pediatrics 2010;125:e1340e1347.

\section{5 \\ Sustained Inflations for Neonates in the Delivery Room - What Is the Evidence?}

H.D. Hummler ${ }^{a}$, A.B. te Pas ${ }^{b}$

${ }^{a}$ Division of Neonatology, Department of Pediatrics, University

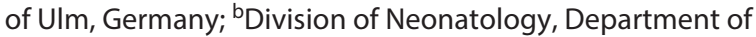
Pediatrics, Leiden University Medical Center, Leiden,

The Netherlands

Recommendations for neonatal resuscitation were often based on weak scientific evidence for many years [1]. Based on the current knowledge, the single most important key element of successful neonatal transition is probably adequate lung aeration immediately after birth [2]. Lung aeration is often impaired in preterm infants because of their poor respiratory effort and instability of their chest wall $[3,4]$. Although chest compressions and/or use of medications are rarely needed during resuscitation, respiratory support may be required especially in preterm infants [5]. Recent studies suggest that less invasive techniques of respiratory support during resuscitation in the delivery room and during early life may help to avoid mechanical ventilation [6-9]. The use of prolonged (sustained) inflations (SI) to overcome the increased resistance, i.e. time constant in a fluid-filled lung, has been described by Vyas et al. [10] in 1981 as an effective method to aerate the lung in intubated asphyxiated term neonates. The noninvasive application of sustained lung inflations as part of a successful noninvasive delivery room management approach for very low birth weight infants was first reported by Lindner et al. [11]. In a series of nicely conducted animal studies, sustained inflations lasting up to $15 \mathrm{~s}$ were shown to aerate the lungs from the first inflation and were associated with a more uniform aeration [12-14]. Currently, only limited clinical data on the effects of SIs for resuscitation in preterm infants are available. Harling et al. [15] randomly assigned preterm infants $(n=52)$ to a 2 - versus a 5 -second SI as the initial inflation and found no difference in proinflammatory pulmonary cytokines as the primary outcome. Lindner et al. [6] found no differences in death or respiratory outcomes comparing a strategy using 15-second SIs with regular intermittent positive pressure ventilation. The study was closed early due to low recruitment and therefore has only limited power to detect differences in relevant outcomes. However, there was a trend to a lower rate of subsequent failure of continuous positive airway pressure (CPAP) in the SI group. A strategy using SIs with 10-second duration at $20 \mathrm{~cm} \mathrm{H}_{2} \mathrm{O}$ pressure, use of nasal intermittent mandatory ventilation and CPAP as compared to bag and mask ventilation in the delivery room without subsequent use of noninvasive respiratory support reduced the rate of infants needing intubation and mechanical ventilation and the rate of bronchopulmonary dysplasia [7]. Since a bundle of interventions was tested in this study, it is difficult to judge the impact of SIs alone. Another study used a strategy using initial SIs with positive end-expiratory pressure/ CPAP immediately after birth and found a reduced rate of intubation/mechanical ventilation and bronchopulmonary dysplasia in preterm infants as compared to historical controls using intermittent positive pressure ventilation/CPAP [16]. Another randomized controlled study on the effects of SIs on the need for mechanical ventilation has finished patient recruitment recently, but results of this study have not been published [17]. In theory, overdistension during SI may cause air leaks and may impair venous return and decrease cardiac output, as suggested by animal studies using large inflation pressures, i.e. tidal volumes for $5 \mathrm{~s}[18,19]$. In contrast, the increase in pulmonary blood flow at birth was not impeded and carotid blood flow did not change when an SI $\left(40 \mathrm{~cm} \mathrm{H}_{2} \mathrm{O}\right.$ for $1 \mathrm{~min}$ or until a tidal volume of $20 \mathrm{ml} / \mathrm{kg}$ was administered) was applied in preterm lambs at birth [14]. No relevant adverse effects using SIs, such as an increased rate of pulmonary air leaks, intraventricular hemorrhage or negative hemodynamic effects, were found in the randomized trials so far $[6,7,16]$. One study showed that very low birth weight infants supported using a standardized protocol including SIs increased their cerebral oxygen saturation at least as fast as full-term infants not requiring any respiratory support [20]. However, the limited evidence available based on the clinical trials mentioned above does not suggest that there may be an increased risk for these adverse outcomes. In summary, the use of SIs may be a useful mode of respiratory support to aerate the lung of preterm infants with poor respiratory effort and may help to improve noninvasive concepts of delivery room care. However, further studies are needed to assess the appropriate pressure and inflation duration, and to study the effects of different interfaces such as masks or prongs. Large randomized controlled trials are needed to prove efficacy and safety of SIs in different term and preterm populations before SIs can be generally recommended. A large, National Institute of Child Health and Human Development-sponsered trial assessing the effects of SIs on survival without bronchopulmonary dysplasia in 600 preterm infants with a gestational age of 23-26 weeks in the USA, Australia, The Netherlands, Italy and Germany is going to start patient recruitment very soon.

\section{References}

1 Obladen M: History of neonatal resuscitation. Part 1: artificial ventilation. Neonatology 2008;94:144-149.

2 te Pas AB, Davis PG, Hooper SB, Morley CJ: From liquid to air: breathing after birth. J Pediatr 2008;152:607-611. 
3 Heldt GP, McIlroy MB: Distortion of chest wall and work of diaphragm in preterm infants. J Appl Physiol 1987;62:164-169.

4 Deoras KS, Greenspan JS, Wolfson MR, et al: Effects of inspiratory resistive loading on chest wall motion and ventilation: differences between preterm and full-term infants. Pediatr Res 1992;32:589-594.

-5 Perlman JM, Wyllie J, Kattwinkel J, Atkins DL, Chameides L, Goldsmith JP, Guinsburg R, Hazinski MF, Morley C, Richmond S, Simon WM, Singhal N, Szyld E, Tamura M, Velaphi S; Neonatal Resuscitation Chapter Collaborators: Part 11: neonatal resuscitation: 2010 International Consensus on Cardiopulmonary Resuscitation and Emergency Cardiovascular Care Science with Treatment Recommendations. Circulation 2010;122:S516-S538.

6 Lindner W, Högel J, Pohlandt F: Sustained pressure-controlled inflation or intermittent mandatory ventilation in preterm infants in the delivery room? A randomized, controlled trial on initial respiratory support via nasopharyngeal tube. Acta Paediatr 2005;94:303-309.

$\checkmark 7$ te Pas AB, Walther FJ: A randomized, controlled trial of delivery-room respiratory management in very preterm infants. Pediatrics 2007;120: 322-329.

$\checkmark 8$ Morley CJ, Davis PG, Doyle LW, et al: Nasal CPAP or intubation at birth for very preterm infants. N Engl J Med 2008;358:700-708.

-9 SUPPORT Study Group of the Eunice Kennedy Shriver NICHD Neonatal Research Network, Finer NN, Carlo WA, Walsh MC, et al: Early CPAP versus surfactant in extremely preterm infants. N Engl J Med 2010; 362:1970-1979.

10 Vyas H, Milner AD, Hopkin IE, Boon AW: Physiologic responses to prolonged and slow-rise inflation in the resuscitation of the asphyxiated newborn infant. J Pediatr 1981;99:635-639.

11 Lindner W, Vossbeck S, Hummler H, Pohlandt F: Delivery room management of extremely low birth weight infants: spontaneous breathing or intubation? Pediatrics 1999;103:961-967.

12 te Pas AB, Siew M, Wallace MJ, et al: Establishing functional residual capacity at birth: the effect of sustained inflation and positive end-expiratory pressure in a preterm rabbit model. Pediatr Res 2009;65:537-541.

13 te Pas AB, Siew M, Wallace MJ, et al: Effect of sustained inflation length on establishing functional residual capacity at birth in ventilated premature rabbits. Pediatr Res 2009;66:295-300.

14 Sobotka KS, Hooper SB, Allison BJ, et al: An initial sustained inflation improves the respiratory and cardiovascular transition at birth in preterm lambs. Pediatr Res 2011;70:56-60.

15 Harling AE, Beresford MW, Vince GS, et al: Does sustained lung inflation at resuscitation reduce lung injury in the preterm infant? Arch Dis Child Fetal Neonatal Ed 2005;90:F406-F410.

$\checkmark 16$ Lista G, Fontana P, Castoldi F, et al: Does sustained lung inflation at birth improve outcome of preterm infants at risk for respiratory distress syndrome? Neonatology 2011;99:45-50.

17 Dani C, Lista G, Pratesi S, et al: Sustained lung inflation in the delivery room in preterm infants at high risk of respiratory distress syndrome (SLI STUDY): study protocol for a randomized controlled trial. Trials 2013;14:67.

18 Björklund LJ, Ingimarsson J, Curstedt T, et al: Manual ventilation with a few large breaths at birth compromises the therapeutic effect of subsequent surfactant replacement in immature lambs. Pediatr Res 1997;42: 348-355.

$\checkmark 19$ Ingimarsson J, Björklund LJ, Curstedt T, et al: A lung recruitment maneuver immediately before rescue surfactant therapy does not affect the lung mechanical response in immature lambs with respiratory distress syndrome. Acta Anaesthesiol Scand 2003;47:968-972.

20 Almaazmi M, Schmid MB, Havers S, et al: Cerebral near-infrared spectroscopy during transition of healthy term newborns. Neonatology 2013; 103:246-251.

\section{Face Mask or Nasal Prong Immediately after Birth?}

C.P.F. O'Donnell

National Maternity Hospital, National Children's Research

Centre, School of Medicine and Medical Science, University

College Dublin, Dublin, Ireland

Most preterm infants breathe spontaneously at birth [1]. A meta-analysis of large randomised trials demonstrated that supporting spontaneous breathing with continuous positive airway pressure (CPAP) at birth, in preference to routine intubation for surfactant administration and/or mechanical ventilation, leads to a reduction in mortality or chronic lung disease in preterm infants [2]. The majority of preterm newborns receive breathing support. This breathing support is given with manual ventilation devices most often via a face mask, but occasionally via a nasal prong (AKA nasal tube/nasopharyngeal tube), a shortened endotracheal tube inserted into the infant's nasopharynx. A single-centre retrospective cohort study showed that the introduction of a multifaceted intervention that included using a single nasal prong instead of a face mask more than halved the rate of intubation in the delivery room (DR) and was associated with reductions in the rates of intubation during hospitalisation and chronic lung disease [3]. A randomised study of a similar multifaceted intervention demonstrated $>50 \%$ reduction in the rate of DR intubation, and reductions in the rates of intubation within $72 \mathrm{~h}$ and of moderate-tosevere bronchopulmonary dysplasia [4]. As the interface was only one of several differences in the respiratory support the groups received (others included the ventilation device used, use of positive end-expiratory pressure and timing of starting CPAP) in both of these studies, it is not possible to determine the relative contribution of the interface to the differences observed between the groups. The effect of using a nasal prong instead of a face mask was examined in two unblinded randomised trials, the MONT trial [5] and the DROPOM trial [6]. In both trials, very preterm infants were randomised before birth to receive respiratory support with a T-piece via a nasal prong or face mask. In the MONT trial, infants received $21 \% \mathrm{O}_{2}$ via either a $7-\mathrm{cm}$ nasal prong or a Laerdal mask, while in the DROPOM trial they received $30 \% \mathrm{O}_{2}$ via a $5-\mathrm{cm}$ prong or a Fisher and Paykel mask. Infants in MONT were intubated in the DR if they remained apnoeic and bradycardic despite positive pressure ventilation, if they received chest compressions or if they had oxygen saturation $\left(\mathrm{SpO}_{2}\right)<85 \%$ despite CPAP of $8 \mathrm{~cm} \mathrm{H}_{2} \mathrm{O}$ in $40 \% \mathrm{O}_{2}$. In DROPOM, infants were intubated in the DR if they had apnoea and/or bradycardia despite positive pressure ventilation. MONT infants who were stabilised on CPAP were all transferred to the neonatal intensive care unit on CPAP via a nasal prong, whereas infants in DROPOM stabilised on CPAP were transferred to the neonatal intensive care unit on their allocated interface. The primary outcome of the MONT trial was intubation for pre-determined failure criteria within $24 \mathrm{~h}$ of birth (one or more $\mathrm{SpO}_{2}<88 \%$ despite CPAP $8 \mathrm{~cm} \mathrm{H}_{2} \mathrm{O}$ in $>40 \% \mathrm{O}_{2}$, apnoea despite caffeine or respiratory acidosis on blood gas). The primary outcome of the DROPOM trial was intubation in the DR; the decision to intubate thereafter was at the discretion of the treating clinician. MONT planned to enrol 648 infants in an attempt to show a $20 \%$ reduction (from 55 to 44\%) in the rate of intubation within $24 \mathrm{~h}$ with nasal prong. DROPOM planned to enrol 142 infants to attempt to show a $40 \%$ reduction (from 62 to $37 \%$ ) in the rate of DR intubation with 
nasal prong. Enrolment to MONT was stopped after interim analysis showed that the chances of finding a difference in the primary outcome between the groups was remote. A total of 363 infants (mean gestational age 27 weeks and body weight 1,012 g) were enrolled. There were no differences between the groups in the rate of intubation $<24$ h (prong $54 \%$ vs. mask $55 \%$ ) or in the DR (23 vs. $31 \%$ ), or in important secondary outcomes between the groups. A total of 144 infants (mean gestational age 28 weeks and body weight $1,117 \mathrm{~g}$ ) were enrolled in the DROPOM trial. There were no differences in the rates of intubation in the DR (prong 15\% vs. mask $15 \%)$ or $<72 \mathrm{~h}$ (67 vs. $63 \%$ ), or in important secondary outcomes between the groups. Neither study demonstrated a difference in DR intubation. In the DROPOM trial, though there was no difference between the groups, there was a dramatic reduction in the rate of DR intubation overall. The rate of intubation in DROPOM outside the DR should be interpreted with caution as the indication for intubation was not standardised. While the studies may not be large enough to exclude small differences in the rate of outcomes between the groups, these differences would be of a magnitude that would be of dubious clinical importance. Face mask and nasal prong appear to be equally effective and safe interfaces for supporting preterm newborns; the choice should be determined by preferences of the carers.

\section{References}

1 O'Donnell CPF, Kamlin COF, Davis PG, Morley CJ: Crying and breathing by extremely preterm infants immediately after birth. J Pediatr 2010; 156:846-847.

2 Rojas-Reyes MX, Morley CJ, Soll R: Prophylactic versus selective use of surfactant for preventing morbidity and mortality in preterm infants. Cochrane Database Syst Rev 2012;3:CD000510.

-3 Lindner W, Vossbeck S, Hummler H, Pohlandt F: Delivery room management of extremely low birth weight infants: spontaneous breathing or intubation? Pediatrics 1999;103:961-967.

4 te Pas AB, Walther F: A randomized, controlled trial of delivery-room respiratory management in very preterm infants. Pediatrics 2007;120: 322-329.

5 Kamlin COF, Schilleman K, Dawson JA, et al: Mask versus nasal tube for stabilization of preterm infants at birth: a randomized controlled trial. Pediatrics 2013;132:e381-e388.

-6 McCarthy LK, Twomey AR, Molloy EJ, et al: A randomized trial of nasal prong or face mask for respiratory support for preterm infants. Pediatrics 2013;132:e389-e395.

\section{7 \\ Delayed Cord Clamping for All Neonates?}

\section{N.E. Vain ${ }^{a}$, D.S. Satragno ${ }^{b}$}

aHospital Sanatorio Trinidad, University of Buenos Aires, and

${ }^{b}$ Children's Hospital Ricardo Gutiérrez, Buenos Aires, Argentina

Although the clamping of the umbilical cord appears as a simple procedure, its timing and the way it is performed have significant effects. Its influence on the neonatal period as well as infancy and later development is frequently underestimated. Furthermore, the impact needs to be taken in perspective: there are approximately 350 births per minute in the world in which the procedure is necessarily performed [1]. The description by Erasmus Darwin [2] of this practice in 1801 resembles a hot topic of discussion nowadays: he then recommended 'tying and cutting' the umbilical cord 'only after pulsation ceased and the child has repeatedly breathed' [1]. It has been known for a long time that delaying cord clamping (DCC) allows the flow of blood from the placenta to the infant, known as placental transfusion. The volume of this transfusion has been estimated by measuring residual volume at the placenta, by the increment in weight of the infant after birth and even by performing actual measurements of the infants' blood volume [3-5]. It can be estimated that when the cord is clamped immediately after birth, $33 \%$ of the infants' blood volume will remain at the placenta, but if the cord is left unclamped to the end of placental transfusion, the residual volume would result in only 13\% [5]. Gravity and the onset of respiration may also influence the volume of transfusion and have been the matter of investigation and controversy $[3,6]$. A recent Cochrane review evaluated 15 randomized controlled trials comparing early (before $60 \mathrm{~s}$ ) versus delayed cord clamping in term newborns involving 3,911 maternal infant dyads [7]. They found with DCC a weight increment (mean $101 \mathrm{~g}$, 95\% CI 45-157 g) representing a placental transfusion of approximately $96 \mathrm{ml}$. They also found higher hemoglobin levels in the neonatal period and increased iron stores at 3-6 months of age in infants with DCC. Only one of the studies reported a marginal increase in infants requiring phototherapy in the DCC group. This review did not confirm any maternal complication (such as the previously reported increased frequency of postpartum hemorrhage). It is concluded that DCC should be recommended for term newborns in all places with available phototherapy. Several professional organizations currently recommend DCC $[8,9]$. However, the compliance with the recommendation appears low [10]. Some obstetricians may still fear about postpartum hemorrhage, and in other cases cord blood banking may prompt an earlier clamping of the cord. However, a major issue which may relate with this low compliance is the suggested effect of gravity on the volume of placental transfusion and the proposal of holding the infant during the period the cord is unclamped at the level of the vagina or even lower. To hold a crying and slippery infant in this way for $2 \mathrm{~min}$ or even longer is uncomfortable, unnatural and delays the possibility of immediate contact with the mother [11]. The potential decrease in the volume of placental transfusion for infants held above the level of the placenta is mostly based on the study by Yao and Lind [3], where infants were placed at different vertical levels above and below the placenta and various timings of clamping the umbilical cord were performed. By measuring placental residual volume they concluded that gravity has a significant influence. However, that evidence was not obtained in conditions similar to those of the real scenario of vaginal deliveries. In the study by Ceriani Cernadas et al. [12], infants were held above the level of the placenta, on their mother's arms in vaginal deliveries and on their laps during DCC, and an increment in hemoglobin was still demonstrated. A Cochrane review concluded that there is insufficient evidence on the influence of gravity [13]. We recently reported a randomized controlled trial in normal term infants born by vaginal delivery [14]. In all cases, we obtained the infants' initial weight immediately after birth; 197 infants were held at the level of the vagina and 194 on their mothers' abdomen or chest, and in all cases the cord was clamped and cut at $2 \mathrm{~min}$, and a second weight measurement was performed. The average weight gain was $55 \mathrm{~g}$, with no differences between groups, even in the subgroup of infants whose mothers adopted a semi-sitting position. We concluded that gravity does not influence the volume of placen- 
tal transfusion. We expect our study to help increasing the compliance with the recommendation of DCC in term infants born by vaginal delivery, which may result in a decreased risk of iron deficiency in infancy, a serious public health problem all over the world, and at the same time enhance maternal-infant bonding by allowing mothers contact with their infant immediately after birth. In premature infants, several studies and meta-analyses suggested some positive effects of DCC: stabilization of blood pressure and circulation, decreased need for blood transfusions, and lower incidences of intraventricular hemorrhage and necrotizing enterocolitis [15]. Recent studies in lambs have suggested that when resuscitation is needed, a smoother cardiovascular transition is obtained when ventilation is initiated without clamping the umbilical cord [16]. There are ongoing studies evaluating this possibility. In conclusion, DCC is an important maneuver showing many short- and long-term benefits in vigorous term and preterm infants, but with potential advantages even in infants needing resuscitation.

References

1 United Nations, Department of Economic and Social Affairs, Population Division: World Population Prospects: The 2012 Revision. New York, United Nations, 2013.

2 Darwin E: Zoonomia, ed 3. Dublin, Dugdale, 1801, vol 3, p 302.

-3 Yao AC, Lind J: Effect of gravity on placental transfusion. Lancet 1969;ii:505-508.

4 Gunther M: The transfer of blood between baby and placenta in the minutes after birth. Lancet 1957;269:1277-1280.

5 Yao AC, Moinian M, Lind J: Distribution of blood between infant and placenta after birth. Lancet 1969;ii:871-873.

-6 Redmond A, Isana S, Ingall D: Relation of onset of respiration to placental transfusion. Lancet 1965;i:283-285.

-7 McDonald SJ, Middleton P, Dowswell T, Morris PS: Effect of timing of umbilical cord clamping of term infants on maternal and neonatal outcomes. Cochrane Database Syst Rev 2013;7:CD004074.

-8 Perlman JM, Wyllie J, Kattwinkel J, Atkins DL, Chameides L, Goldsmith JP, Guinsburg R, Hazinski MF, Morley C, Richmond S, Simon WM, Singhal N, Szyld E, Tamura M, Velaphi S; Neonatal Resuscitation Chapter Collaborators: Part 11: neonatal Resuscitation: 2010 International Consensus on Cardiopulmonary Resuscitation and Emergency Cardiovascular Care Science with Treatment Recommendations. Circulation 2010;122:S516-S538.

-9 Sweet DG, Carnielli V, Greisen G, et al: European consensus guidelines on the management of neonatal respiratory distress syndrome in preterm infants - 2013 update. Neonatology 2013;103:353-368.

10 Hutchon DJ: Why do obstetricians and midwives still rush to clamp the cord? BMJ 2010;341:c5447.

11 Raju TN: Delayed cord clamping: does gravity matter? Lancet 2014; pii:S0140-6736(14)60411-6.

12 Ceriani Cernadas JM, Carroli G, Pellegrini L, et al: The effect of timing of cord clamping on neonatal venous hematocrit values and clinical outcome at term: a randomized, controlled trial. Pediatrics 2006; 117:e779-e786

13 Airey RJ, Farrar D, Duley L: Alternative positions for the baby at birth before clamping the umbilical cord. Cochrane Database Syst Rev 2010; 6:CD007555.

14 Vain NE, Satragno DS, Gorenstein AN, et al: Effect of gravity on volume of placental transfusion: a multicentre, randomised, non-inferiority trial. Lancet 2014;pii:S0140-6736(14)60197-5.

15 Rabe H, Diaz-Rossello JL, Duley L, Dowswell T: Effect of timing of umbilical cord clamping and other strategies to influence placental transfusion at preterm birth on maternal and infant outcomes. Cochrane Database Syst Rev 2012;8:CD003248.

16 Bhatt S, Alison BJ, Wallace EM, et al: Delaying cord clamping until ventilation onset improves cardiovascular function at birth in preterm lambs. J Physiol 2013;591:2113-2126.

\section{Nasal Continuous Positive Airway Pressure or High-Flow Nasal Cannula?}

\section{R. Ramanathan, M. Biniwale}

Division of Neonatal Medicine, Department of Pediatrics, Los Angeles County, and University of Southern California Medical Center and Children's Hospital Los Angeles, Keck School of Medicine, University of Southern California, Los Angeles, Calif., USA

Nasal continuous positive airway pressure (NCPAP) is provided using a water column (bubble CPAP), a flow generator (infant flow driver) or a conventional ventilator. The user controls the pressure generated by varying the resistance to expiratory flow. Bubble CPAP systems use a constant gas flow rate that is set by the user, and the CPAP generated is assumed to be equal to the length of expiratory tubing that is immersed under water. Even during bubble CPAP, increasing the flow rate will result in an increase in intra-prong pressures at the level of the patient's nasal interface [1]. Tubing submersion depth during bubble CPAP is highly inaccurate, and care providers should instead rely on intra-prong pressure measurements. A major problem with the use of nasal prongs is the risk of nasal injuries, such as columellar necrosis and nasal deformities [2-5]. Furthermore, nasal mucosal injury acts as a site of entry for bacteria, resulting in nosocomial sepsis in preterm neonates [6]. Heated, high-flow nasal cannula (HHFNC) systems are increasingly being used due their ease of use. Because of high flows, they do generate substantial CPAP at the upper airways of infants [7-10]. One of the major limitations is that the pressure delivered is unpredictable and depends on the flow rates used, length and internal diameter of the nasal cannula, and the amount of leak at the nostrils. Nasal cannulas ( 0.2 and $0.3 \mathrm{~cm}$ in outer diameter) could generate up to $9.8 \mathrm{~cm} \mathrm{H}_{2} \mathrm{O}$ at flow rates of $2 \mathrm{l} / \mathrm{min}$ [10]. This positive distending pressure effect was felt to improve both oxygenation and thoracoabdominal synchrony. Serious complications, such as scalp emphysema, pneumo-orbitis and pneumocephalus, have been reported with use of HHFNC [11]. To decrease the delivered pressure during HHFNC, manufacturers have decreased the inner diameter of the nasal cannula or use a uninasal cannula. Nasopharyngeal washout of the dead space, better humidification and high bulk flow to match the inspiratory flow demands in patients who are tachypneic are some of the potential effects during HHFNC. However, higher humidification at the nasopharyngeal level does not translate into better humidification at the lower airways given the open-circuit design. Since pressures generated are neither measured nor controlled by the user, flow rates $>21 / \mathrm{min}$ should not be used in preterm neonates. HHFNC systems are expensive compared to bubble CPAP systems. Preterm infants needing respiratory support should be stabilized with NCPAP. Since NCPAP failures leading to intubation are very high in infants with extremely low birth weight $[12,13]$, clinicians should consider starting nasal intermittent positive pressure ventilation as soon as possible in these infants, followed by weaning from NCPAP and subsequent use of a low-flow nasal cannula $(<2 \mathrm{l} / \mathrm{min})$. Additional studies are needed to evaluate the safety and efficacy of using HHFNC before it can be recommended for use in preterm neonates. The costs of HHFNC systems over bubble CPAP have to be taken into consideration given the lack of evidence for equivalency or superiority in resource-limited parts of the world. 


\section{References}

1 Kahn DJ, Courtney SE, Steele AM, Habib RH: Unpredictability of delivered bubble nasal continuous positive airway pressure: role of bias flow magnitude and nares-prong air leaks. Pediatr Res 2007;62:343-347.

$\checkmark 2$ Robertson J, McCarthy S, Hamilton A, Moss L: Nasal deformities resulting from flow driver continuous positive airway pressure. Arch Dis Child Fetal Neonatal Ed 1996;75:F209-F212.

- 3 Jatana KR, Oplatek A, Stein M, et al: Effects of nasal continuous positive airway pressure and cannula use in the neonatal intensive care unit setting. Arch Otolaryngol Head Neck Surg 2010;136:287-291.

-4 Fischer C, Bertelle V, Hohlfeld J, et al: Nasal trauma due to continuous positive airway pressure in neonates. Arch Dis Child Fetal Neonatal Ed 2010;95:F447-F451.

5 Yong SC, Chen CJ, Boo NY: Incidence of nasal trauma associated with nasal prong versus nasal mask during continuous positive airway pressure treatment in very low birthweight infants: a randomized control study. Arch Dis Child Fetal Neonatal Ed 2005;90:480-483.

-6 Rønnestad A, Abrahamsen TG, Medbø S, et al: Septicemia in the first week of life in a Norwegian national cohort of extremely premature infants. Pediatrics 2005;115:e262-e268.

7 Wilkinson DJ, Andersen CC, Smith K, Holberton J: Pharyngeal pressure with high-flow nasal cannulae in premature infants. J Perinatol 2008;28: $42-47$.

8 Kubicka ZJ, Limauro J, Darnall RA: Heated, humidified high-flow nasal cannula therapy: yet another way to deliver continuous positive airway pressure? Pediatrics 2008;121:82-88.

9 Frey B, Shann F: Oxygen administration in infants. Arch Dis Child Fetal Neonatal Ed 2003;88:F84-F88.

10 Locke RG, Wolfson MR, Shaffer TH, et al: Inadvertent administration of positive end-distending pressure during nasal cannula flow. Pediatrics 1993; $91: 135-138$.

11 Jasin LR, Kern S, Thompson S, et al: Subcutaneous scalp emphysema, pneumo-orbitis and pneumocephalus in a neonate on high humidity high flow nasal cannula. J Perinatol 2008;28:779-781.

12 Ramanathan R, Paz P, Biniwale M: Non-invasive ventilation and surfactant therapy. J Pulmon Resp Med 2013;S13:006..

$\checkmark 13$ Kirpalani H, Millar D, Lemrye B, et al: A trial comparing noninvasive ventilation strategies in preterm infants. N Engl J Med 2013;369:611620

\section{9}

\section{Should We Be Supporting Very Low Birth Weight Infants with High-Flow Nasal Cannulae or Continuous Positive Airway Pressure - Favoring High-Flow Cannulae}

\section{C.C. Roehr}

Newborn Services, John Radcliffe Hospital, Oxford University Hospitals, Oxford, UK; The Ritchie Centre, Monash Institute of Medical Research, Monash University, Melbourne, Australia; Department of Neonatology, Charité University Medical Centre, Berlin, Germany

This paper describes the use of non-invasive continuous distending pressure (CDP) as respiratory support for preterm infants. Continuous positive airway pressure (CPAP) and heated and humidified high-flow nasal cannulae (HFNC) are particularly discussed. The application of CDP has become the mainstay of respiratory management of neonates with respiratory distress [1]. Attributed effects are splinting of the upper and lower airways, increases in pulmonary gas volume and functional residual capacity, improvement in gas exchange and oxygenation, stabilization of spontaneous respiration and reduction in apnoea $[2,3]$. Concerning our current understanding of CPAP, it is a widely held belief that CPAP is a stringent, pressure-controlled modality. However, investigations in the effect of mouth opening and leak under CPAP have clearly demonstrated that the measured tidal volume is significantly reduced with mouth opening and leak flow easily exceeds $20 \%$ of bias flow [4]. Since Gregory [5] introduced CDP pressure into neonatal care as head box CPAP in 1971 the application of CDP has evolved over single nasal prong to binasal prong CPAP [6]. A plethora of different CPAP devices is now available. Apart from technical differences, there is wide inter-institutional variation in CPAP practice, for instance the optimal CPAP level remains a matter of debate: for example a starting CPAP from 3 to $10 \mathrm{~cm} \mathrm{H}_{2} \mathrm{O}$ is being used in Germany [7]. Irrespective of the universal use of this treatment, nasal CPAP is prone to significant unwanted effects, such as cranial deformities, pressure sores, nasal erythema and necrosis, abdominal symptoms, pneumothorax and potentially sepsis [8]. Nasal cannulae have long been used to deliver oxygen to infants with chronic respiratory compromise and/or hypoxaemia [9]. A flow rate $>11 / \mathrm{min}$ is regarded as 'high flow' [10]. Flows of non-heated, dry gas of 0.5-2 l/ min were found to exsiccate the nasal mucosa and increase airway resistance. Humidification of medical gas without sufficient heating causes condensation and droplet aspiration. Recent technical improvements have evolved in small HFNC, which provide flows of up to $40 \mathrm{l} / \mathrm{min}$ of sufficiently heated and humidified gas. HFNC works via nasal prong interfaces like most CPAP devices, but the two systems differ significantly in their mode of action. Nasal CDP is generated within the CPAP device where the resistance is provided by the expiratory valve or water lock. In HFNC, CDP is developed within the nose or oro-pharynx as a result of the flow through the cannula combined with the infant's spontaneous respiration. Conversely, the resistance is determined by the leak between the nares and the cannula [11]. Different to nasal CPAP where physiological and clinical properties have been studied over decades, until recently, laboratory and clinical data on HFNC have remained scant [12]. HFNC has incorrectly been touted as 'poor man's CPAP' and was criticized as unscientific. New scientific evidence from bench-top and clinical studies has helped to understand HFNC mechanisms of action $[11,13]$. It is understood that HFNC flush the nasopharyngeal dead space thereby allowing for more effective alveolar ventilation and oxygenation, provide sufficient flow to help reduce inspiratory work of breathing and reduce metabolic expenditure [14]. The efficacy of HFNC has now been investigated in over 20 controlled clinical trials. However, particularly some of the earlier trials were limited by insufficient power and/or poor methodology [15]. Recent large, prospective randomized controlled trials have compared HFNC to CPAP (3 trials) or nasal intermittent positive pressure ventilation (1 trial) as post-extubation treatment. Together, they include over 800 neonates. Results of these trials show that HFNC was as safe to use and not inferior to CPAP or nasal intermittent positive pressure ventilation [16-19]. Two studies found less nasal trauma in the HFNC groups. Klingenberg et al. [20] investigated patient comfort under CPAP and HFNC. They found no significant difference in comfort scores, but improved parental satisfaction in the HFNC group. Large, multicentre trials to investigate the use of HFNC as primary treatment for the respiratory distress syndrome are currently 
under way. To summarize, HFNC have been shown to be efficacious and safe in very low birth weight infants after extubation, whereas the use of HFNC as a primary therapy for the respiratory distress syndrome requires further study. HFNC evolves as an easy-to-use alternative to nasal CPAP for certain clinical scenarios. It has lesser side effects and achieves higher nursing and parental contentment. Future trials should investigate for which type of infant and clinical condition HFNC proves to be most beneficial.

\section{References}

$\checkmark 1$ Morley C: Continuous distending pressure. Arch Dis Child Fetal Neonatal Ed 1999;81:F152-F156.

- 2 Ho JJ, Subramaniam P, Henderson-Smart DJ, Davis PG: Continuous distending pressure for respiratory distress syndrome in preterm infants. Cochrane Database Syst Rev 2002;2:CD002271.

3 Courtney SE, Barrington KJ: Continuous positive airway pressure and non-invasive ventilation. Clin Perinatol 2007;34:79-92.

-4 Fischer HS, Roehr CC, Proquitté H, et al: Is volume and leak monitoring feasible during nasopharyngeal continuous positive airway pressure in neonates? Intensive Care Med 2009;35:1934-1941.

5 Gregory GA, Kitterman JA, Phibbs RH, et al: Treatment of the idiopathic respiratory-distress syndrome with continuous positive airway pressure. N Engl J Med 1971;284:1333-1340.

-6 De Paoli AG, Davis PG, Faber B, Morley CJ: Devices and pressure sources for administration of nasal continuous positive airway pressure (NCPAP) in pre-term neonates. Cochrane Database Syst Rev 2008; 1:CD002977.

7 Roehr CC, Schmalisch G, Khakban A, et al: Use of continuous positive airway pressure (CPAP) in neonatal units - a survey of current preferences and practice in Germany. Eur J Med Res 2007;26:139-144.

8 Aly H, Hammad TA, Ozen M, et al: Nasal colonization among premature infants treated with nasal continuous positive airway pressure. Am J Perinatol 2011;28:315-320.

-9 Kopelman AE, Holbert D: Use of oxygen cannulas in extremely low birthweight infants is associated with mucosal trauma and bleeding, and possibly with coagulase-negative staphylococcal sepsis. J Perinatol 2003; 23:94-97.

10 Wilkinson D, Andersen C, O’Donnell CP, De Paoli AG: High flow nasal cannula for respiratory support in preterm infants. Cochrane Database Syst Rev 2011;5:CD006405.

11 Lavizzari A, Veneroni C, Colnaghi M, et al: Respiratory mechanics during NCPAP and HHHFNC at equal distending pressures. Arch Dis Child Fetal Neonatal Ed 2014, Epub ahead of print.

12 Morley CJ, Davis PG: Continuous positive airway pressure: scientific and clinical rationale. Curr Opin Pediatr 2008;20:119-124.

13 Sivieri EM, Gerdes JS, Abbasi S: Effect of HFNC flow rate, cannula size, and nares diameter on generated airway pressures: an in vitro study. Pediatr Pulmonol 2013;4:506-514.

14 de Jongh BE, Locke R, Mackley A, et al: Work of breathing indices in infants with respiratory insufficiency receiving high-flow nasal cannula and nasal continuous positive airway pressure. J Perinatol 2014;34:2732.

15 Manley BJ, Dold SK, Davis PG, Roehr CC: High-flow nasal cannulae for respiratory support of preterm infants: a review of the evidence. Neonatology 2012;102:300-308.

16 Collins CL, Holberton JR, Barfield C, Davis PG: A randomized controlled trial to compare heated humidified high-flow nasal cannulae with nasal continuous positive airway pressure postextubation in premature infants. J Pediatr 2013;162:949.e1-954.e1.

17 Manley BJ, Owen LS, Doyle LW, et al: High-flow nasal cannulae in very preterm infants after extubation. N Engl J Med 2013;369:1425-1433.

18 Yoder BA, Stoddard RA, Li M, et al: Heated, humidified high-flow nasal cannula versus nasal CPAP for respiratory support in neonates. Pediatrics 2013;131:e1482-e1490.
19 Kugelman A, Riskin A, Said W, et al: A randomized pilot study comparing heated humidified high-flow nasal cannulae with NIPPV for RDS. Pediatr Pulmonol 2014, Epub ahead of print.

20 Klingenberg C, Pettersen M, Hansen EA, et al: Patient comfort during treatment with heated humidified high flow nasal cannulae versus nasal continuous positive airway pressure: a randomised cross-over trial. Arch Dis Child Fetal Neonatal Ed 2014;99:F134-F137.

\section{0 \\ Practical Issues of Targeting Oxygen in the Neonatal Unit}

\section{B.J. Stenson}

Department of Neonatology, Royal Infirmary of Edinburgh, Edinburgh, UK

Background: There is wide variation in practice regarding oxygen targeting for preterm infants. Trials in the 1950s, before targeting was possible, linked unrestricted oxygen to retinopathy of prematurity. The subsequent oxygen restriction increased mortality [1]. Blood gas analysers and transcutaneous $\mathrm{PO}_{2}$ monitoring permitted targeting but the optimal $\mathrm{PO}_{2}$ target range was never determined. Guidelines recommended a range of $50-80 \mathrm{~mm} \mathrm{Hg}$ [2]. Pulse oximeter saturation $\left(\mathrm{SpO}_{2}\right)$ monitoring became the norm but it was introduced with little investigation. No trials were performed to show that it would improve outcomes in comparison with $\mathrm{PO}_{2}$ monitoring and none were done to determine the optimal $\mathrm{SpO}_{2}$ range. A $\mathrm{SpO}_{2}$ range of $85-95 \%$ was considered acceptable [2]. $\mathrm{PO}_{2}$ and $\mathrm{SpO}_{2}$ are not linearly related and it is important to note that the $95 \%$ confidence intervals of $\mathrm{PO}_{2}$ for the $\mathrm{SpO}_{2}$ range $85-95 \%$ in oxygen-dependent preterm infants are around 28-67 $\mathrm{mm} \mathrm{Hg}(3.8-8.9 \mathrm{kPa})$ [3], so the introduction of $\mathrm{SpO}_{2}$ monitoring was associated with a substantial unresearched shift downwards in targeted $\mathrm{PO}_{2}$ levels from previous recommendations. Recent Evidence: Five similar trials of $\mathrm{SpO}_{2}$ targeting for preterm infants have now been published [4-8]. Three trials have reported followup outcomes $[5,7,8]$ and 2 have reported outcomes to hospital discharge [6], with follow-up outcomes anticipated shortly. The evidence has been summarised in a meta-analysis by Saugstad and Aune [9]. Mortality and Morbidity: Data from 4,884 infants in the 5 trials show that the lower $\mathrm{SpO}_{2}$ target range was associated with increased mortality [ 19.3 vs. $16.2 \%$, relative risk $(R R)=1.18(1.04-$ 1.34)]. The point estimates for mortality from 4 of the 5 trials favoured higher $\mathrm{SpO}_{2}$. The exception was BOOST (Benefits of Oxygen Saturation Targeting) II New Zealand which contributed 340 of the 4,884 infants. The $95 \%$ confidence intervals of the RR for mortality from the New Zealand trial (0.51-1.51) include those of the overall meta-analysis. The data from these trials probably underestimate the mortality risk of the lower $\mathrm{SpO}_{2}$ range. Mid-way through the trials a problem with the oximeter calibration was identified [10]. This was corrected in 3 of the trials, allowing more effective targeting, and meta-analysis of the outcomes of the 1,725 infants treated with the revised oximeters showed an RR for mortality with lower versus higher $\mathrm{SpO}_{2}$ targets of 1.41 (1.14-1.74) [10]. Mortality was $21.1 \%$ in the low target group and $15.3 \%$ in the high target group. The revised oximeters are similar to other oximeters in widespread use [10] and this may be the more generalis- 
able mortality risk estimate. Hazard plots from the trials show that the difference in mortality arose gradually over many weeks. Necrotising enterocolitis affected $11.2 \%$ of infants in the low target group and $9.0 \%$ of infants in the high target group, RR 1.25 (1.051.49). Severe retinopathy of prematurity affected $10.7 \%$ of the low target group and $14.5 \%$ of the high target group, RR 0.74 (0.59$0.92)$. There was no significant difference between groups in any other reported short-term morbidity. Disability: Three of the trials have reported outcomes to 18 or 24 months $[5,7,8]$. There is so far no evidence that disability is increased in either randomisation group. Blindness is rare in both groups. The remaining data will be reported in 2014. Future Practice: These trials show conclusively that the intended $\mathrm{SpO}_{2}$ target range influences mortality and morbidity. Further studies will be required, but the present evidence should influence practice. The mortality risk of lower $\mathrm{SpO}_{2}$ targets outweighs any other adverse outcome. Retinopathy of prematurity is a serious condition but it can usually be treated and, although it is associated with adverse neurodevelopmental outcome, the same is true of necrotising enterocolitis. Achieved versus Intended $\mathrm{SpO}_{2}$ : The trial results are probably attributable to the achieved $\mathrm{SpO}_{2}$ patterns. In the BOOST II UK and Australia trials, histograms of the percentage of time that infants spent at each $\mathrm{SpO}_{2}$ value showed that in both study groups, the achieved $\mathrm{SpO}_{2}$ values were higher than intended. The high target group had the peak of their distribution at $94 \%$. The low target group had their peak at $90 \%$. It was a distribution of achieved $\mathrm{SpO}_{2}$ centred around $90 \%$ that was associated with increased mortality in the low target group. The other trials have not published detailed information about their achieved $\mathrm{SpO}_{2}$ but the available information suggests that achieved $\mathrm{SpO}_{2}$ in their low target groups was also higher than intended. The trial results may therefore be underestimating the risks of maintaining $\mathrm{SpO}_{2}$ at values below 90\%. Many infants are difficult to target and it is impossible to keep them within a narrow range at all times. Units vary in their success in achieving intended $\mathrm{SpO}_{2}$ targets [11]. A greater focus on ensuring that oximeter alarm limits are set and adhered to will be necessary [12]. Compliance is better when alarm limits are set to the intended range rather than being wider [11]. Compliance is better when nurse staffing ratios are higher [13]. Staffing is important because the outcomes in the trials were determined over many weeks and not just the early days after birth. Servo-control systems are becoming available [14]. These appear to be more effective than manual control in delivering intended $\mathrm{SpO}_{2}$ and will be capable of influencing clinical outcome. Because they are likely to result in a lower $\mathrm{SpO}_{2}$ distribution than would be observed with routine nurse control, servo systems could worsen rather than improve outcome if they are not researched carefully to identify the control settings required to optimise outcomes. More than ever before there is evidence that oxygen saturation targets influence outcome. Every neonatal unit should have a clear policy on targeting and should audit their achieved saturation patterns.

\section{References}

1 Silverman WA: A cautionary tale about supplemental oxygen: the albatross of neonatal medicine. Pediatrics 2004;113:394-396.

2 American Academy of Pediatrics, American College of Obstetricians and Gynecologists: Guidelines for Perinatal Care, ed 6. Elk Grove Village, American Academy of Pediatrics, 2007.

-3 Quine D, Stenson BJ: $\mathrm{PaO}_{2}$ values in infants $<29$ weeks of gestation at currently targeted saturations. Arch Dis Child Fetal Neonatal Ed 2009; 94:F51-F53.
4 SUPPORT Study Group of the Eunice Kennedy Shriver NICHD Neonatal Research Network, Carlo WA, Finer NN, Walsh MC, et al: Target ranges of oxygen saturation in extremely preterm infants. N Engl J Med 2010;362:1959-1969.

5 Vaucher YE, Peralta-Carcelen M, Finer NN, et al; SUPPORT Study Group of the Eunice Kennedy Shriver NICHD Neonatal Research Network: Neurodevelopmental outcomes in the early CPAP and pulse oximetry trial. N Engl J Med 2012;367:2495-2504.

6 6 BOOST II United Kingdom Collaborative Group; BOOST II Australia Collaborative Group; BOOST II New Zealand Collaborative Group, Stenson BJ, Tarnow-Mordi WO, Darlow BA, et al: Oxygen saturation and outcomes in preterm infants. N Engl J Med 2013;368:2094-2104.

7 Schmidt B, Whyte RK, Asztalos EV, Moddemann D, Poets C, Rabi Y, Solimano A, Roberts RS; Canadian Oxygen Trial (COT) Group: Effects of targeting higher vs lower arterial oxygen saturations on death or disability in extremely preterm infants: a randomized clinical trial. JAMA 2013;309:2111-2120.

8 Darlow BA, Marschner SL, Donoghoe M, Battin MR, Broadbent RS, Elder MJ, Hewson MP, Meyer MP, Ghadge A, Graham P, McNeill NJ, Kuschel CA, Tarnow-Mordi WO; Benefits of Oxygen Saturation Targeting-New Zealand (BOOST-NZ) Collaborative Group: Randomized controlled trial of oxygen saturation targets in very preterm infants: two year outcomes. J Pediatr 2014;pii:S0022-3476(14)00023-7.

-9 Saugstad OD, Aune D: Optimal oxygenation of extremely low birth weight infants: a meta-analysis and systematic review of the oxygen saturation target studies. Neonatology 2014;105:55-63.

10 Johnston ED, Boyle B, Juszczak E, et al: Oxygen targeting in preterm infants using the Masimo SET Radical pulse oximeter. Arch Dis Child Fetal Neonatal Ed 2011;96:F429-F433.

11 Hagadorn JI, Furey AM, Nghiem TH, Schmid CH, Phelps DL, Pillers DA, Cole CH; AVIOx Study Group: Achieved versus intended pulse oximeter saturation in infants born less than 28 weeks' gestation: the AVIOx study. Pediatrics 2006;118:1574-1582.

12 Nghiem TH, Hagadorn JI, Terrin N, et al: Nurse opinions and pulse oximeter saturation target limits for preterm infants. Pediatrics 2008; 121:e1039-e1046.

13 Sink DW, Hope SA, Hagadorn JI: Nurse:patient ratio and achievement of oxygen saturation goals in premature infants. Arch Dis Child Fetal Neonatal Ed 2011;96:F93-F98.

14 Claure N, Bancalari E, D'Ugard C, et al: Multicenter crossover study of automated control of inspired oxygen in ventilated preterm infants. Pediatrics 2011;127:e76-e83.

\section{1 \\ Is Nasal Ventilation a Good Alternative for Invasive Intermittent Positive Pressure Ventilation?}

\section{E. Bancalari, D. Jain}

Division of Neonatology, Department of Pediatrics, University of Miami Miller School of Medicine, Miami, Fla., USA

The management of respiratory failure with invasive intermittent positive pressure ventilation (IPPV) has been one of the key factors responsible for improving survival of extremely premature infants. Though lifesaving, invasive IPPV is associated with a significant risk of acute lung injury and long-term pulmonary morbidity. For these reasons, there has been a concerted effort to explore less invasive alternatives to maintain gas exchange while minimizing complications associated with invasive IPPV in these infants. Two alternatives of nasal support, nasal continuous positive airway pressure (NCPAP) and nasal IPPV (NIPPV), have been 
studied extensively in the last 3 decades, with varying success. Both NCPAP and NIPPV can stabilize lung volume resulting in improved gas exchange, less apnea and reduced upper airway obstruction and thoracoabdominal asynchrony. As initial respiratory support strategy, NCPAP has been studied in several large randomized controlled trials, all of which showed similar incidence of bronchopulmonary dysplasia (BPD) with use of CPAP when compared to invasive mechanical ventilation $[1,2]$. A recent metaanalysis of these studies showed a modest decrease in the rates of BPD or death at 36 weeks postmenstrual age with early use of CPAP rather than intubation and mechanical ventilation [3]. However, these studies included relatively mature infants with a high antenatal steroid use, but still a large proportion of the infants in the CPAP groups required mechanical ventilation and surfactant administration during the first days after birth. Because of the high prevalence of failure with NCPAP, especially in smaller and sicker infants, there has been a resurgence of NIPPV use in preterm infants as an alternative for invasive support. Used as an initial strategy for the respiratory distress syndrome, NIPPV has had mixed results with some small studies showing significant benefit and reduction for the need of invasive ventilation [4]. However, the largest multicenter randomized controlled trial comparing NCPAP with NIPPV for both treatment of the respiratory distress syndrome and respiratory support after extubation failed to show any significant decrease in the incidence of BPD or death with NIPPV use [5]. Some of the reasons for the inconsistent results between different trials could be differences in patient populations with different background risk of BPD, and the variability in the settings and equipment used in different studies. In contrast, NIPPV has consistently been shown to be superior to NCPAP for the prevention of extubation failure. Some of these studies have also shown trends towards decreased rates of BPD in the NIPPV group compared to NCPAP [6]. One of the possible mechanisms why NIPPV is superior to CPAP is the higher mean airway pressure achieved during NIPPV. Synchronization of NIPPV cycles with the patient's inspiration can increase the transpulmonary pressure, which may be an additional mechanism to explain the improved outcomes with NIPPV. Though there have been some physiological studies showing decreased work of breathing with synchronized NIPPV as compared to NIPPV [7], there has been no randomized controlled study comparing the two modalities with respect to BPD or other long-term respiratory outcomes. One of the newer methods available for synchronization is neurally adjusted ventilator assist, which uses the electrical activity of the diaphragm to detect spontaneous inspiration and delivers positive pressure in proportion to the electrical signal from the diaphragm [8]. There are some short-term studies in small groups of preterm infants suggesting that this modality improves patient-ventilator interaction and reduces respiratory effort, but there are no longterm outcome data in this population. In conclusion, though nasal ventilation is used very commonly and has shown some short-term physiological advantages over NCPAP, evidence for long-term benefits in respiratory outcomes is not consistent. Furthermore, there are still many unanswered questions such as what NIPPV settings to use, the potential advantage of synchronization and the best way to achieve synchronization. Importantly, there is no evidence that NIPPV use is associated with an increased risk of adverse effects. Nasal ventilation is a viable alternative to invasive IPPV for many of the preterm infants, both as initial respiratory strategy as well as an adjunct to decrease extubation failure. Still, a large pro- portion of the smaller and more immature infants are likely to fail and require invasive IPPV. It is important for clinicians to identify these infants early in their respiratory course to avoid complications associated with inadequate respiratory support.

\section{References}

1 Finer NN, Carlo WA, Walsh MC, et al: Early CPAP versus surfactant in extremely preterm infants. N Engl J Med 2010;362:1970-1977.

2 Dunn MS, Kaempf J, Howard D, et al: Randomized trial comparing 3 approaches to the initial respiratory management of preterm neonates. Pediatrics 2011;128:e1069-e1076.

-3 Schmolzer GM, Kumar M, Cheung P, et al: Non-invasive versus invasive respiratory support in preterm infants at birth: systematic review and meta-analysis. BMJ 2013;347:f5980.

4 Kugelman A, Feferkorn I, Riskin A, et al: Nasal intermittent mandatory ventilation versus nasal continuous positive airway pressure for respiratory distress syndrome: a randomized, controlled prospective study. J Pediatr 2007;150:521-526.

5 Kirpalani H, Millar D, Roberts RS, et al: A trial comparing noninvasive ventilation strategies in preterm infants. N Engl J Med 2013;369:611620 .

6 Moretti C, Giannini L, Fassi C, et al: Nasal flow-synchronized intermittent positive pressure ventilation to facilitate weaning in very low-birthweight infants: unmasked randomized controlled trial. Pediatr Int 2008; 50:85-91.

7 Chang HY, Claure N, Bancalari E, et al: Effects of synchronization during nasal ventilation in clinically stable preterm infants. Pediatr Res 2011;69: 84-89.

8 Beck J, Reilly M, Sinderby C, et al: Patient-ventilator interaction during neurally adjusted ventilatory assist in very low birth weight infants. Pediatr Res 2009;65:663-668.

\section{2}

\section{Bronchopulmonary Dysplasia: Past, Present and Future}

\section{A.G.S. Philip}

Division of Neonatal and Developmental Medicine, Stanford University School of Medicine, Palo Alto, Calif., USA

It is now approximately 50 years since the introduction of assisted ventilation to manage infants with the respiratory distress syndrome (RDS), formerly called hyaline membrane disease. Shortly afterwards, in 1967, the first description of bronchopulmonary dysplasia (BPD) was published [1]. Initial reports suggested that BPD was the result of exposure to very high oxygen concentrations administered by assisted ventilation $[1,2]$. In 1975 , I proposed that BPD was related not only to exposure of the immature lung to increased oxygen concentrations, but also to positive pressure ventilation administered over an extended period of time [3]. More recently, I (and others) suggested that it was most likely part of a continuum of pathology that includes the Wilson-Mikity syndrome [4-6] and might be better called chronic lung disease of prematurity [5,6]. During the 1970s and 1980s, neonatologists dealt with a disorder that could be quite devastating, requiring weeks to months of assisted ventilation. This resulted in prolonged hospital stays and only gradual improvement in pulmonary function, or death from either cor pulmonale or severe fibrosis. The majority of infants who survived had been born with a gestational age of 28 
weeks or more. After the initial report in 1980 of the successful administration of exogenous surfactant to treat RDS [7], extensive studies of surfactant were performed around the world and surfactants for use in RDS were approved by the Food and Drug Administration of the USA starting in 1990. Over the ensuing decade, many more extremely preterm infants survived, some with chronic lung disease. The infants who formerly had developed BPD ( $>27$ weeks gestation) were now spared chronic lung disease, but the less mature infants developed what Jobe described as 'new BPD' [8]. In contrast to airway injury with alternating areas of overinflation and fibrosis of the lung parenchyma, 'new BPD' was characterized by arrested pulmonary development. Currently, a diagnosis of BPD is based largely on continued oxygen requirement at 36 weeks postmenstrual age, rather than on radiographic features of macrocystic and hyperinflated lungs. However, BPD may be overdiagnosed in some centers, because the use of oxygen saturation monitors has resulted in overuse of oxygen to maintain 'good' oxygen saturation [9]. Among the many preventive and therapeutic strategies for RDS (and consequently for BPD) that are currently available, antenatal corticosteroids and exogenous surfactant have proved to be the most efficacious $[2,10,11]$. This is particularly true for those whose gestational age is $>27$ weeks. However, caffeine and to some extend vitamin A may have a place in the management of BPD [12]. The role of postnatal corticosteroids remains debatable. At the present time, increasing emphasis is placed on the early use of continuous positive airway pressure (CPAP) as a preventive strategy. This approach was proposed in the 1980s [13], but more recent studies provide increasing evidence that early noninvasive CPAP (rather than proceeding directly to endotracheal intubation) may result in a decrease in the incidence of BPD $[14,15]$. It seems likely that avoidance of endotracheal intubation and using minimally invasive surfactant techniques will be the approach in the future to prevent BPD $[16,17]$. One recent study demonstrated a marked decrease in the incidence of BPD when surfactant was given by thin catheter during spontaneous breathing rather than using the InSurE technique (intubation, surfactant and extubation). In neonates with gestational age $<28$ weeks, BPD incidence was reported to be 13.6 versus $26.2 \%$, respectively [18]. For those at risk for or who develop BPD, the possibility of using stem cells to prevent and/or treat BPD has been proposed. Bone marrow-derived mesenchymal stem cells (MSCs) have attracted the most attention and may prevent impaired alveolar and lung vascular development in oxygen-induced lung injury [19]. They may also attenuate lung inflammation and fibrosis [19]. MSCs have also been derived from human cord blood and shown to preserve both alveolar and lung vascular growth as well as lung function and to prevent pulmonary hypertension in rodents exposed to hyperoxia [19]. Additionally, after 2 weeks of oxygen exposure, airway delivery of MSCs restored alveolar growth and lung function in rats. Amniotic fluid stem cells may have similar effects to MSCs [19]. Whether or not such promotion of both lung repair and lung growth can be achieved in human newborn infants remains to be seen.

\section{References}

1 Northway WH Jr, Rosan RC, Porter DY: Pulmonary disease following respirator therapy of hyaline membrane disease: bronchopulmonary dysplasia. N Engl J Med 1967;276:357-368.

$\checkmark 2$ Hawker JM, Reynolds EOR, Taghizadeh A: Pulmonary surface tension and pathological changes in infants dying after respirator treatment for severe hyaline membrane disease. Lancet 1967;ii:75-77.
3 Philip AGS: Oxygen plus pressure plus time: the etiology of bronchopulmonary dysplasia. Pediatrics 1975;55:45-50.

4 Hodgman JE: Relationship between Wilson-Mikity syndrome and the new bronchopulmonary dysplasia. Pediatrics 2003;112:1414-1415.

5 Philip AGS: Chronic lung disease of prematurity: a short history. Semin Fetal Neonatal Med 2009;14:333-338.

6 Philip AGS: Bronchopulmonary dysplasia: then and now. Neonatology 2012;102:1-8.

7 Fujiwara T, Maeta H, Chida S, et al: Artificial surfactant therapy in hyaline membrane disease. Lancet 1980;i:55-59.

8 Jobe AJ: The new BPD: an arrest of lung development. Pediatr Res 1999; 46:641-643.

9 Walsh MC, Yao Q, Gettner PP, Hale E, Collins M, Hensman A, Everette R, Peters N, Miller N, Muran G, Auten K, Newman N, Rowan G, Grisby C, Arnell K, Miller L, Ball B, McDavid G; National Institute of Child Health and Human Development Neonatal Research Network: Impact of a physiologic definition on bronchopulmonary dysplasia rates. Pediatrics 2004;114:1305-1311.

10 Sweet DG, Carnielli V, Greisen G, et al: European consensus guidelines on the management of neonatal respiratory distress syndrome in preterm infants - 2013 update. Neonatology 2013;103:353-368.

11 Speer CP, Sweet DG: Surfactant replacement: present and future; in Bancalari E (ed): The Newborn Lung, ed 2. Philadelphia, Elsevier Saunders, 2012, pp 283-299.

12 Thomas W, Speer CP: Chorioamnionitis: important risk factor or innocent bystander for neonatal outcome? Neonatology 2011;99:177-187.

13 Avery ME, Tooley WH, Keller JE, et al: Is chronic lung disease in low birth weight infants preventable? A survey of eight centers. Pediatrics 1987;79:26-30

14 Finer NN, Carlo WA, Walsh MC, et al: Early CPAP versus surfactant in extremely preterm infants. N Engl J Med 2010;362:1970-1979.

15 Dunn MS, Kaempf J, de Klerk A, de Klerk R, Reilly M, Howard D, Ferrelli K, O'Conor J, Soll RF; Vermont-Oxford Network DRM Study Group: Randomized trial comparing 3 approaches to the initial respiratory management of preterm neonates. Pediatrics 2011;128:e1069e1076.

16 Göpel W, Kribs A, Ziegler A, Laux R, Hoehn T, Wieg C, Siegel J, Avenarius S, von der Wense A, Vochem M, Groneck P, Weller U, Möller J, Härtel C, Haller S, Roth B, Herting E; German Neonatal Network: Avoidance of mechanical ventilation by surfactant treatment of spontaneously breathing preterm infants (AMV): an open-label, randomised, controlled trial. Lancet 2011;378:1627-1634.

17 Dargaville PA: Innovation in surfactant therapy I: surfactant lavage and surfactant administration by fluid bolus using minimally invasive techniques. Neonatology 2012;101:326-336.

18 Kanmar HG, Erdeve O, Canpolat FE, et al: Surfactant administration via thin catheter during spontaneous breathing: a randomized controlled trial. Pediatrics 2013;131:e502-e509.

19 Thébaud B: Chronic lung disease in the neonate: past, present and future. NeoReviews 2013,14:e252-e258.

\section{3 \\ Mesenchymal Stem Cells in Preterm Infants: The Magic Cure of Bronchopulmonary Dysplasia?}

Y.S. Chang, W.S. Park

Department of Pediatrics, Sungkyunkwan University School of

Medicine, Seoul, Korea

Bronchopulmonary dysplasia (BPD) is a chronic lung disease which follows ventilator and oxygen therapy in very preterm infants [1]. Although the number of very premature infants at a high 
risk for developing BPD is increasing because of advances in neonatal intensive care [2], BPD remains a major cause of mortality and lifelong morbidity without any effective ways of prevention or treatment having been developed yet [3]. Several recent studies have shown that mesenchymal stem cells (MSCs) attenuate hyperoxia-induced neonatal lung injury which simulates BPD in human infants, such as impaired alveolarization, increased inflammation, increased apoptosis and fibrosis [4-8]. Human umbilical cord blood (hUCB) is considered a better source of MSCs than other potential sources, such as bone marrow or adipose tissue, because of their ready availability and greater proliferative capacity and less antigenicity [9]. We have performed several preclinical studies regarding optimal route [4], dose [7] and timing [8] of hUCB-derived MSC transplantation in a neonatal hyperoxic lung injury model in rat pups. The benefits of MSC transplantation are primarily mediated by a paracrine rather than a regenerative mechanism $[4,6]$, and vascular endothelial growth factor secreted by transplanted MSCs is at least one of the critical paracrine factors that play seminal roles in attenuating hyperoxic lung injuries in neonatal rats [10]. We have also shown that the protection of MSCs against neonatal hyperoxic lung injury was persistent, and that no long-term toxicities, adverse effects or tumorigenicity were present 70 days after transplantation [11]. For the successful clinical translation of transplantation of hUCB-derived MSCS for an effective treatment of BPD, various preclinical toxicity and safety tests were done using hUCB-derived MSCs, which were produced with good manufacturing practices and tested with karyotype stability at up to passage $11[4,12]$. Finally, we performed a phase I doseescalating clinical study on the safety and feasibility of transplantation of hUCB-derived MSCs in preterm infants at high risk for developing BPD [12]. Intratracheal MSC transplantation was performed $10.4 \pm 2.6$ days after birth in 9 premature infants with gestational ages of $25.3 \pm 0.9$ weeks and birth weights of $793 \pm 127 \mathrm{~g}$. The first 3 patients were given a low dose $\left(1 \times 10^{7}\right.$ cells $\left./ \mathrm{kg}\right)$ of cells; the next 6 patients were given a high dose $\left(2 \times 10^{7}\right.$ cells $\left./ \mathrm{kg}\right)$. We compared the adverse outcomes including BPD severity in them with those in historical nested case-matched controls. The treatments were well tolerated, and no patients experienced serious adverse effects or dose-limiting toxicities attributable to the transplantation. When compared to the matched controls, BPD severity was lower and the other adverse outcome rates were not different in transplant recipients. Taken together, intratracheal transplantation of allogeneic hUCB-derived MSCs in preterm infants is safe and feasible, and warrants larger and controlled phase II as well as long-term follow-up studies.

\section{References}

$\checkmark 1$ Avery ME, Tooley WH, Keller JB, et al: Is chronic lung disease in low birth weight infants preventable? A survey of eight centers. Pediatrics 1987;79:26-30.

2 Stoll BJ, Hansen NI, Bell EF, et al: Neonatal outcomes of extremely preterm infants from the NICHD Neonatal Research Network. Pediatrics 2010;126:443-456.

-3 Bregman J, Farrell EE: Neurodevelopmental outcome in infants with bronchopulmonary dysplasia. Clin Perinatol 1992;19:673-694.

4 Chang YS, Oh W, Choi SJ, et al: Human umbilical cord blood-derived mesenchymal stem cells attenuate hyperoxia-induced lung injury in neonatal rats. Cell Transplant 2009;18:869-886.

5 van Haaften T, Byrne R, Bonnet S, et al: Airway delivery of mesenchymal stem cells prevents arrested alveolar growth in neonatal lung injury in rats. Am J Respir Crit Care Med 2009;180:1131-1142.
6 Abman SH, Matthay MA: Mesenchymal stem cells for the prevention of bronchopulmonary dysplasia: delivering the secretome. Am J Respir Crit Care Med 2009;180:1039-1041.

7 Chang YS, Choi SJ, Sung DK, et al: Intratracheal transplantation of human umbilical cord blood-derived mesenchymal stem cells dose-dependently attenuates hyperoxia-induced lung injury in neonatal rats. Cell Transplant 2011;20:1843-1854.

8 Chang YS, Choi SJ, Ahn SY, et al: Timing of umbilical cord blood derived mesenchymal stem cells transplantation determines therapeutic efficacy in the neonatal hyperoxic lung injury. PLoS One 2013;8:e52419.

-9 Le Blanc K: Immunomodulatory effects of fetal and adult mesenchymal stem cells. Cytotherapy 2003;5:485-489.

10 Chang YS, Ahn SY, Jeon HB, et al: Critical role of VEGF secreted by mesenchymal stem cells in hyperoxic lung injury. Am J Respir Cell Mol Biol 2014, Epub ahead of print.

11 Ahn SY, Chang YS, Kim SY, et al: Long-term (postnatal day 70) outcome and safety of intratracheal transplantation of human umbilical cord blood-derived mesenchymal stem cells in neonatal hyperoxic lung injury. Yonsei Med J 2013;54:416-424.

12 Chang YS, Ahn SY, Yoo HS, et al: Mesenchymal stem cells for bronchopulmonary dysplasia: phase 1 dose-escalation clinical trial. J Pediatr 2014;164:966-972.

\section{4 \\ Patent Ductus Arteriosus: Increased Risk of Bronchopulmonary Dysplasia?}

\section{E. Bancalari}

Division of Neonatology, Department of Pediatrics, University of Miami Miller School of Medicine, Miami, Fla., USA

The increased pulmonary blood flow resulting from left to right ductal shunting can negatively impact lung development and function and delay recovery from the respiratory distress syndrome [1, 2 ]. Infants with a symptomatic patent ductus arteriosus (PDA) have lower lung compliance and require increased ventilator settings to maintain gas exchange predisposing them to more lung injury [3]. PDA and Lung Development: While the patency of the fetal ductus arteriosus protects the developing pulmonary circulation from overflow, the patency of the ductus after birth exposes the pulmonary vessels to excessive blood flow and pressure, which can negatively affect the development of the vasculature and alveolar structure, and increase the risk of bronchopulmonary dysplasia (BPD) [4]. Both vascular endothelial growth factor (VEGF) and transforming growth factor (TGF)- $\beta$ are key to lung development. Fetal lambs with increased pulmonary blood flow and hypertension show decreased VEGF expression shortly after birth [5]. Decreased expression of VEGF is also seen in preterm infants with severe respiratory distress syndrome and in infants with BPD [6]. In contrast, TGF- $\beta$ expression is increased in animals exposed to increased pulmonary blood flow and also in infants with BPD $[7,8]$. Thus, both VEGF and TGF- $\beta$ expression are affected by increased pulmonary blood flow and vascular pressure, and this may negatively influence lung development and function. Preterm baboons who had early pharmacologic closure of the PDA with ibuprofen on day 3 had better alveolar development and improved alveolar surface area than animals where the PDA remained open [9]. PDA and BPD: Despite the evidence that increased flow and pressure in the developing pulmonary vasculature can affect lung 
development, the role of the PDA in the pathogenesis of BPD is not clear. Several epidemiological studies have found an increased incidence of BPD in infants with symptomatic PDA $[10,11]$, but there are scarce data from prospective randomized clinical trials (RCTs) supporting this association. Closure of the PDA is associated with rapid improvement in lung mechanics [12]. However, two meta-analyses failed to demonstrate a decrease in long-term pulmonary morbidity when prophylactic indomethacin treatment was compared to later treatment of a symptomatic PDA $[13,14]$. It is important to note that most infants randomized to the control arm of these trials received indomethacin soon after the symptoms of the PDA appeared and, therefore, were not exposed to the effects of a prolonged increased pulmonary blood flow. A recent metaanalysis showed that PDA treatment with intravenous ibuprofen was associated with an increased risk of BPD compared to treatment with indomethacin. [15]. However, no significant difference in BPD incidence was found in infants who received indomethacin versus placebo. Several RCTs have compared early PDA closure versus delayed treatment when signs of left heart failure are more evident. Even when the time difference between early and late closure was relatively small, most studies have demonstrated that early PDA closure was associated with decreased pulmonary morbidity and duration of mechanical ventilation $[13,16]$. Van Overmeire et al. [17] did not find significant differences in respiratory outcome between infants who received 'early' (day 3) compared to 'late' indomethacin (day 7). However, infants were relatively mature and half of the patients in the 'late' treatment group had spontaneous PDA closure by day 9. In a review of the literature, Benitz [18] concluded that there was no evidence that routine closure of the ductus was beneficial in preterm infants. However, this conclusion is not supported by the results of the review that showed a significant decrease in death or chronic lung disease in infants receiving early versus late treatment for their PDA. In a recent RCT, infants with mild signs of PDA were randomized to 'early' treatment with ibuprofen or 'expectant management" receiving placebo [19]. Infants who developed a hemodynamically significant PDA received open label ibuprofen. No significant differences were found in BPD or any other clinical outcome between the two groups leading to the conclusion that infants with mild signs of PDA may not benefit from early PDA treatment. In another RCT conducted in Australia, infants $<29$ weeks were screened for a large PDA and if confirmed received indomethacin or placebo before $12 \mathrm{~h}$ of age. [20] There was no difference in the primary outcome death or abnormal cranial ultrasound or in BPD between the two treatment groups. However, infants receiving early indomethacin had significantly less early pulmonary hemorrhage. The 72 nonrandomized infants with a small PDA had an $80 \%$ spontaneous PDA closure rate. The main argument for a conservative approach to the PDA is the fact that many will close spontaneously, avoiding the use of drugs or surgery, both therapies associated with significant complications. However, spontaneous PDA closure rate is gestational age dependent, being much lower in the more immature infant who is at higher risk of severe BPD. The two most recent trials suggest that while it may not be advisable to routinely treat relatively small PDAs that are not hemodynamically significant, large PDAs with significant hemodynamic impact should be treated to avoid the acute and long-term consequences of pulmonary overflow. The difficulty is in defining what a hemodynamically significant PDA is.

\section{References}

Jacob J, Gluck L, DiSessa T, et al: The contribution of PDA in the neonate with severe RDS. J Pediatr 1980;96:79-87.

- 2 Kitterman JA, Edmunds LH, Gregory GA, et al: Patent ductus arteriosus in premature infants. Incidence, relation to pulmonary disease and management. N Engl J Med 1972;287:473-477.

3 Heldt GP, Personen E, Merritt TA, et al: Closure of the ductus arteriosus and mechanics of breathing in preterm infants after surfactant replacement. Pediatr Res 1989;25:305-310.

4 Morin FC 3rd: Ligating the ductus arteriosus before birth causes persistent pulmonary hypertension in the newborn lamb. Pediatr Res 1989;25: 245-250.

5 Grover TR, Parker TA, Zenge JP, et al: Intrauterine hypertension decreases lung VEGF expression and VEGF inhibition causes pulmonary hypertension in the ovine fetus. Am J Physiol Lung Cell Mol Physiol 2003;284:L508-L517.

6 6 Bhatt AJ, Pryhuber GS, Huyck H, et al: Disrupted pulmonary vasculature and decreased vascular endothelial growth factor, Flt-1, and TIE-2 in human infants dying with bronchopulmonary dysplasia. Am J Respir Crit Care Med 2001;164:1971-1980.

7 Mata-Greenwood E, Meyrick B, Steinhorn RH, et al: Alterations in TGF- $\beta 1$ expression in lambs with increased pulmonary blood flow and pulmonary hypertension. Am J Physiol Lung Cell Mol Physiol 2003; 285:L209-L221.

8 Kotecha S, Wangoo A, Silverman M, Shaw RJ: Increase in the concentration of transforming growth factor beta- 1 in bronchoalveolar lavage fluid before development of chronic lung disease of prematurity. J Pediatr 1996;128:464-469.

-9 McCurnin D, Seidner S, Chang LY, et al: Ibuprofen-induced patent ductus arteriosus closure: physiologic, histologic, and biochemical effects on the premature lung. Pediatrics 2008;121:945-956.

10 Gonzalez A, Sosenko IRS, Chandar J, et al: Influence of infection on patent ductus arteriosus and chronic lung disease in premature infants weighing 1000 grams or less. J Pediatr 1996;128:470-478.

11 Rojas MA, Gonzalez A, Bancalari E, et al: Changing trends in the epidemiology and pathogenesis of neonatal chronic lung disease. J Pediatr 1995; 126:605-610.

12 Gerhardt T, Bancalari E: Lung compliance in newborns with patent ductus arteriosus before and after surgical ligation. Biol Neonate 1980;38: 96-105.

13 Clyman RI: Recommendations for the postnatal use of indomethacin: an analysis of four separate treatment strategies. J Pediatr 1996;128:601607.

14 Fowlie PW, Davis PG: Prophylactic intravenous indomethacin for preventing mortality and morbidity in preterm infants. Cochrane Database Syst Rev 2002;3:CD000174.

15 Jones LJ, Craven PD, Attia J, et al: Network meta-analysis of indomethacin versus ibuprofen versus placebo for PDA in preterm infants. Arch Dis Child Fetal Neonatal Ed 2011;96:F45-F52.

16 Cotton RB, Hickey DE, Graham TP, Stahlman MT: Effect of early indomethacin on ventilatory status of preterm infants with symptomatic patent ductus arteriosus. Pediatr Res 1980;14:442.

17 Van Overmeire B, Van de Brock H, Van Laer P, et al: Early versus late indomethacin treatment for patent ductus arteriosus in premature infants with respiratory distress syndrome. J Pediatr 2001;138:205-211.

18 Benitz WE: Treatment of persistent patent ductus arteriosus in preterm infants: time to accept the null hypothesis? J Perinatol 2010;30:241-252.

19 Sosenko IRS, Fajardo F, Claure N, Bancalari E: Timing of patent ductus arteriosus treatment and respiratory outcome in premature infants: a double-blind randomized controlled trial. J Pediatr 2012;160:929-935.

20 Kluckow M, Jeffery M, Gill A, Evans N: A randomized placebo-controlled trial of early treatment of the patent ductus arteriosus. Arch Dis Child Fetal Neonatal Ed 2014;99:F99-F104. 
15

\section{Patent Ductus Arteriosus: Noli Me Tangere?}

\section{B. van Overmeire}

Department of Neonatology-Pediatrics, Erasmus Hospital, Brussels, Belgium

An increasing number of reports describe that early aggressive treatment of a persistent patent ductus arteriosus (PDA) does not seem to offer many advantages for the preterm baby [1-5]. On the contrary, side effects of nonsteroidal anti-inflammatory drugs, administered either intravenously or orally, may provoke untoward effects on different organ systems [6,7]. In many centers, the trend to a conservative approach is increasing and to wait longer to allow spontaneous closure in the 1st week of life [8]. Various complications, e.g. intraventricular hemorrhage, may rather be explained as comorbidities of prematurity than consequences of the PDA [9, 10]. On the other hand, in some of the smallest extremely low birth weight infants, an early deterioration may be observed and ascribed to the large left-to-right shunt through the duct and the inability of the heart to cope with the increased volume load [11]. The challenge is to recognize early on those babies who will not close their duct and who will rapidly progress to an increased shunt and flooded pulmonary circulation. Clinical signs, demographic and antenatal factors, ultrasound assessments [12] and cardiovascular biomarkers [13] were all tested in dozens of studies for their predictive and discriminating power to detect the hemodynamically important PDA early. Echocardiography may guide both the need and the effect of treatment [14-16]. Nevertheless, a gold standard for the early prediction of a hemodynamically significant ductus arteriosus seems not yet defined. Indomethacin, ibuprofen and more recently paracetamol have been studied at different postnatal ages in order to find the optimal timing of duct closure $[7,17$, 18]. Controversy remains about when, how and if PDA needs to be treated $[19,20]$. This issue will probably not be resolved in the coming years. However, recent and ongoing studies are shedding new light on the 'do not touch strategy'.

\section{References}

$\checkmark 1$ Bose CL, Laughon MM: Patent ductus arteriosus: lack of evidence for common treatments. Arch Dis Child Fetal Neonatal Ed 2007;92:F498F502.

2 Laughon M, Bose C, Benitz WE: Patent ductus arteriosus management: what are the next steps? J Pediatr 2010;157:355-357.

-3 Benitz WE: Treatment of persistent patent ductus arteriosus in preterm infants: time to accept the null hypothesis? J Perinatol 2010;30:241-252.

4 Sosenko IR, Fajardo MF, Claure N, et al: Timing of patent ductus arteriosus treatment and respiratory outcome in premature infants: a double-blind randomized controlled trial. J Pediatr 2012;160:929-935.

$\checkmark 5$ Kluckow M, Jeffery M, Gill A, Evans N: A randomised placebo-controlled trial of early treatment of the patent ductus arteriosus. Arch Dis Child Fetal Neonatal Ed 2014;99:F99-F104.

6 Bagnoli F, Rossetti A, Messina G, et al: Treatment of patent ductus arteriosus (PDA) using ibuprofen: renal side-effects in VLBW and ELBW newborns. J Matern Fetal Neonatal Med 2013;26:423-429.

7 Ohlsson A, Walia R, Shah SS: Ibuprofen for the treatment of patent ductus arteriosus in preterm and/or low birth weight infants. Cochrane Database Syst Rev 2013;4:CD003481.

$\rightarrow 8$ Kulkarni A, Richards J, Duffy D: Survey of management of patent ductus arteriosus in neonatal units across England. Arch Dis Child Fetal Neonatal Ed 2013;98:F465-F466.
9 Brunner B, Hoeck M, Schermer E, et al: Patent ductus arteriosus, low platelets, cyclooxygenase inhibitors, and intraventricular hemorrhage in very low birth weight preterm infants. J Pediatr 2013;163:23-28.

10 Jaleel MA, Rosenfeld CR: Patent ductus arteriosus and intraventricular hemorrhage: a complex association. J Pediatr 2013;163:8-10.

11 Sellmer A, Bjerre JV, Schmidt MR, et al: Morbidity and mortality in preterm neonates with patent ductus arteriosus on day 3. Arch Dis Child Fetal Neonatal Ed 2013;98:F505-F510.

12 Evans N: Diagnosis of the preterm patent ductus arteriosus: clinical signs, biomarkers, or ultrasound? Semin Perinatol 2012;36:114-1122.

13 Grass B, Baumann P, Arlettaz R, et al: Cardiovascular biomarkers proatrial natriuretic peptide and pro-endothelin- 1 to monitor ductus arteriosus evolution in very preterm infants. Early Hum Dev 2014;90:293298.

14 DeMauro SB, Cohen MS, Ratcliffe SJ, et al: Serial echocardiography in very preterm infants: a pilot randomized trial. Acta Paediatr 2013;102: 1048-1053.

15 Bravo MC, Cabañas F, Riera J, et al: Randomised controlled clinical trial of standard versus echocardiographically guided ibuprofen treatment for patent ductus arteriosus in preterm infants: a pilot study. J Matern Fetal Neonatal Med 2014;27:904-909.

16 Clyman R, Wickremasinghe A, Jhaveri N, Hassinger DC, Attridge JT, Sanocka U, Polin R, Gillam-Krakauer M, Reese J, Mammel M, Couser R, Mulrooney N, Yanowitz TD, Derrick M, Jegatheesan P, Walsh M, Fujii A, Porta N, Carey WA, Swanson JR; Ductus Arteriosus Feed or Fast with Indomethacin or Ibuprofen (DAFFII) Investigators: Enteral feeding during indomethacin and ibuprofen treatment of a patent ductus arteriosus. J Pediatr 2013;163:406-411.

17 OncelMY, Yurttutan S, Degirmencioglu H, et al:Intravenous paracetamol treatment in the management of patent ductus arteriosus in extremely low birth weight infants. Neonatology 2013;103:166-169.

18 Alan S, Kahvecioglu D, Erdeve O, et al: Is paracetamol a useful treatment for ibuprofen-resistant patent ductus arteriosus? Neonatology 2013;104: 168-169.

19 Sehgal A, McNamara PJ: The ductus arteriosus: a refined approach! Semin Perinatol 2012;36:105-113.

20 Mitra S, Rønnestad A, Holmstrøm H: Management of patent ductus arteriosus in preterm infants - where do we stand? Congenit Heart Dis 2013;8:500-512.

\section{6}

\section{Benefits and Risks of Parenteral Nutrition and Suggested Guidelines}

W.W. Hay Jr.

Department of Pediatrics, University of Colorado School of Medicine, Aurora, Colo., USA

Intravenous nutrition (IVN) is required in very preterm infants to maintain energy supplies and essential fatty acids and amino acids and to establish an anabolic condition. Glucose: Standard glucose infusion rates in preterm infants start at $\sim 6-8 \mathrm{mg} / \mathrm{min} / \mathrm{kg}$, increasing to $10-14 \mathrm{mg} / \mathrm{min} / \mathrm{kg}$ for full IVN. This practice, however, often leads to hyperglycemia, as most preterm infants maintain glucose production from gluconeogenesis [1] and glycogenolysis, caused by increased cortisol adrenalin, and glucagon, which reduce insulin secretion and insulin action, increase tissue protein breakdown and activate regulatory enzymes in the gluconeogenic pathway. Intravenous lipid infusions provide carbon that competes with glucose carbon, glycerol that fuels gluconeogenesis [2], and metabolic products of free fatty acids (ATP, AcCoA and 
$\mathrm{NADH})$ that activate key gluconeogenic enzymes [3]. Excessive glucose infusion rates $(>11-14 \mathrm{mg} / \mathrm{kg} / \mathrm{min})$ adversely increase fat deposition, energy expenditure, $\mathrm{O}_{2}$ consumption and $\mathrm{CO}_{2}$ production, fatty infiltration of heart and liver and cellular allostatic load [4] with excessive reactive oxygen species that produce inflammation, augmenting cholestatic hepatitis from selective fatty acids in intravenous lipid products [5]. Hyperglycemia also increases the risk of retinopathy of prematurity [6]; insulin could worsen this risk by promoting reactive oxygen species production, while amino acids might help by promoting IGF-1 production, which reduces the risk of retinopathy of prematurity [7]. Tight glucose control with insulin infusions in preterm infants should be used with caution. Insulin actually makes the baby fatter (including fatty infiltration of heart and liver) and increases complications from excess allostatic load and the risk of hypoglycemic episodes [8]. In a study comparing insulin infusion with reduced glucose infusion rates, there was no difference in all age/weight groups on rates of death, sepsis, retinopathy of prematurity, necrotizing enterocolitis, intracranial hemorrhage, chronic lung disease, days in the neonatal intensive care unit or growth [9]. Lipids: Standard intravenous lipid infusions start at $0.5-1.0 \mathrm{~g} / \mathrm{kg} / \mathrm{day}$ at birth and increase to $3.0-3.5 \mathrm{~g} / \mathrm{kg} /$ day over $2-5$ days for full IVN. Unfortunately, this frequently leads to hypertriglyceridemia, as preterm infants have maturational deficiency in lipases and low levels of carnitine palmitoyltransferase. Lipid infusion rates are often reduced to $0.5-1 \mathrm{~g} / \mathrm{kg} /$ day with sepsis, severe lung disease, surgical stress, steroid use, hyperglycemia, cholestasis and chronically reduced carnitine intakes ( $>2$ weeks). There is little scientific evidence to support such practices or to define mechanisms involved and how to manipulate them to promote better fatty acid oxidation. Supplemental carnitine only enhances lipid oxidation when IVN lasts more than weeks as the sole source of nutrition. Amino Acids: Fetal animal growth data predict preterm human amino acid requirements of $3.6-4.8 \mathrm{~g} / \mathrm{kg} / \mathrm{day}$, which are comparable to those obtained by the factorial method [10] that predicts human fetal amino acid requirements of $4 \mathrm{~g} / \mathrm{kg} / \mathrm{day}$ at $24-30$ weeks of gestation. All preterm infants should receive intravenous infusion of amino acids of $2-4 \mathrm{~g} / \mathrm{kg} /$ day starting right after birth. Almost universally, this practice has increased protein balance and reduced hyperglycemia, without consistent evidence for excessive uremia, hyperammonemia, acidosis or high concentrations of potentially toxic amino acids. Only one study has documented such conditions [11]; this study used Aminosyn PF ${ }^{\mathrm{TM}}$ rather than the more commonly used TrophAmine ${ }^{\mathrm{TM}}$, and severity and types of illnesses were not clearly defined. In contrast, most studies have documented inadequate concentrations of essential amino acids and slower than normal growth rates, including length and head circumference $[12,13]$. Clearly, more studies in preterm infants, particularly in those who are sick and/or physiologically unstable, are necessary to determine optimum glucose, lipid and amino acid mixtures and infusion rates.

\section{References}

1 Chacko S, Sunehag A: Arch Dis Child Fetal Neonatal Ed 2010;95:F413F418.

2 Sunehag AL: Parenteral glycerol enhances gluconeogenesis in very premature infants. Pediatr Res 2003;53:635-641.

3 Girard J: Metabolic adaptations to change of nutrition at birth. Biol Neonate 1990;58(suppl 1):3-15.

4 Picard M, Juster RP, McEwen BS: Mitochondrial allostatic load puts the 'gluc' back in glucocorticoids. Nat Rev Endocrinol 2014;10:303-310.
5 El Kasmi KC, Anderson AL, Devereaux MW, et al: Toll-like receptor 4-dependent Kupfer cell activation and liver injury in a novel mouse model of parenteral nutrition and intestinal injury. Hepatology 2012;55: $1518-1528$

6 Chavez-Valdez R, McGowan J, Cannon E, Lehmann CU: Contribution of early glycemic status in the development of severe retinopathy of prematurity in a cohort of ELBW infants. J Perinatol 2011;31:749-756.

7 Hård AL, Smith LE, Hellström A: Nutrition, insulin-like growth factor-1 and retinopathy of prematurity. Semin Fetal Neonatal Med 2013;pii:S1744-165X(13)00007-3.

8 Beardsall K, Vanhaesebrouck S, Ogilvy-Stuart AL, et al: A randomised controlled trial of early insulin therapy in very low birth weight infants, 'NIRTURE' (neonatal insulin replacement therapy in Europe). BMC Pediatr 2007;7:29.

9 Bottino M, Cowett RM, Sinclair JC: Interventions for treatment of neonatal hyperglycemia in very low birth weight infants. Cochrane Database Syst Rev 2009;1:CD007453.

10 Ziegler EE, O’Donnell AM, Nelson SE, Fomon SJ: Body composition of the reference fetus. Growth 1976;40:329-341.

11 Blanco CL, Gong AK, Green BK, et al: Early changes in plasma amino acid concentrations during aggressive nutritional therapy in extremely low birth weight infants. J Pediatr 2011;158:543.e1-548.e1.

12 Clark RH, Chace DH, Spitzer AR; Pediatrix Amino Acid Study Group: Effects of two different doses of amino acid supplementation on growth and blood amino acid levels in premature neonates admitted to the neonatal intensive care unit: a randomized, controlled trial. Pediatrics 2007; 120:1286-1296.

13 Thureen PJ, Hay WW Jr: Early aggressive nutrition in preterm infants. Semin Neonatol 2001;6:403-415.

\section{7}

\section{Nectrotizing Enterocolitis: The Mystery Goes On}

J. Neu

Division of Neonatology, Department of Pediatrics, College of

Medicine, University of Florida, Gainesville, Fla., USA

Necrotizing enterocolitis (NEC) has largely been present in neonatal intensive care units for the past 60 years. NEC prevalence has corresponded with the continued development and sophistication of neonatal intensive care. Despite major efforts towards its eradication, NEC has persisted and appears to be increasing in some centers. The pathophysiology of this disease remains poorly understood. Several issues have hampered our quest to develop a better understanding of this disease. These include the fact that what we have historically termed 'NEC' appears to be several different diseases. Animal models that are commonly used to study NEC pathophysiology and treatment do not directly reflect the most common form of the disease seen in human infants. The pathophysiology appears to be multifactorial reflecting several different pathways to intestinal necrosis with different inciting factors. Spontaneous intestinal perforations, ischemic bowel disease secondary to cardiac anomalies as well as other entities that are clearly different from the most common form of NEC seen in preterm infants have been put into the same database. In the complete article, I describe some of the different forms of what has been called NEC and make some comments on its pathophysiology, where available studies suggest involvement of genetic factors, intestinal immaturity, hemodynamic instability, inflammation and a dysbiotic microbial ecology. Currently utilized approaches for 
the diagnosis of NEC are presented and innovative technologies for the development of diagnostic and predictive biomarkers are described. Predictions for future strategies are also discussed.

The complete review will be published in Neonatology, vol. 106, no. $4,2014$.

\section{8 \\ Necrotising Enterocolitis: Biomarkers for Early Detection and Diagnosis}

H.S. Lam, P.C. Ng

Department of Paediatrics, Prince of Wales Hospital, The Chinese University of Hong Kong, Hong Kong, China

Necrotising enterocolitis (NEC) is the most common and devastating surgical condition that primarily affects preterm infants [1]. It is an acute life-threatening disease that can result in serious long-term complications involving distant organs, especially the brain. Despite its prime involvement of the gastrointestinal (GI) tract, it is often difficult to differentiate NEC from systemic inflammatory conditions such as late-onset sepsis [2]. As the management between NEC and late-onset sepsis is very different with regard to the duration and choice of antibiotics, requirement for transferring to a paediatric surgical centre, prolonged fasting and need for long-term parenteral nutrition, it is important to diagnose NEC early and differentiate it from other infective/inflammatory conditions $[1,3]$. Thus, many recent studies have focused on the discovery of novel biomarkers for early detection of bowel injury. It is now known that different categories of biomarkers of NEC exhibit markedly different properties, and conceptually they can be categorised into three main functional groups [1]: (i) non-specific inflammatory biomarkers or mediators, e.g. acute-phase reactants, cytokines, chemokines and cell surface antigens $[1,2,4-9]$; (ii) 'enhanced' non-specific biomarkers, e.g. faecal inflammatory mediators $[10,11]$, of which the nature of the specimen enhances their tissue specificity, and (iii) gut-specific biomarkers [3, 12]. Each category has its unique set of properties which render them capable of providing different clinical information on the disease [1]. Non-specific inflammatory biomarkers are mediators that are involved in common molecular pathways of inflammation or infection, and they do not specifically differentiate NEC from other infective/inflammatory conditions, e.g. sepsis and tissue necrosis $[1,2,4-9]$. These non-specific biomarkers include acute-phase reactants, e.g. C-reactive protein [2, 7], apolipoproteins and serum amyloid A [4]; cytokines and chemokines, e.g. interleukin-6 and -10, and RANTES (regulated upon activation of normal T-cell expression and secretion) [5], and cell surface antigens, e.g. neutrophil CD64 [2,6]. Although these biomarkers are non-specific, they are very sensitive during early phases of the illness $[2,4,6,9]$ and may, therefore, be useful for early detection of NEC when combined with other investigations, such as abdominal radiograph or ultrasound [2]. Biomarkers with late-phase changes, e.g. C-reactive protein, may be more useful to monitor the disease progress or predict the development of complications [7, 9]. Enhanced non-specific biomarkers are also non-specific inflammatory mediators, but by virtue of the nature of the specimen (i.e. stool) provide information representing the intensified inflammatory response localised to a specific organ (i.e. GI tract). In theory, these biomarkers, e.g. calprotectin, S100A12 and lactoferrin, should better distinguish NEC from other systemic infective/inflammatory conditions. Calprotectin, a neutrophil-secreted peptide, was shown to be increased in faecal specimens of infants with NEC [10]. However, previous studies have small sample sizes and revealed conflicting results $[10,11]$. In particular, a significant decrease in faecal calprotectin concentrations has also been reported in fulminant NEC cases [11]. In addition to the difficulty in defining an optimal cutoff concentration, other limitations include: difficulty in obtaining adequate stool samples in a timely manner because of intestinal ileus, likely heterogeneous distribution of the biomarker in stool samples and normal turnover of peptides in the GI tract resulting in significant overlap in faecal concentrations between infants with and without NEC [1]. Thus, although conceptually attractive, these biomarkers have not yet seen widespread clinical use. Recently, there has been intense interest in investigating the use of gut-specific proteins, which are largely or exclusively expressed in GI cells $[3,12,13]$. As these biomarkers are considered tissue specific, they are expected to be capable of differentiating intra-abdominal inflammation, as in NEC, from systemic infection [1,3]. However, plasma and urine concentrations of many gut-specific proteins, e.g. intestinal fatty acid binding protein (FABP), liver-FABP, trefoil factor-3 and claudin-3, are increased only in infants with severe, widespread GI inflammation [3]. The combined use of liver-FABP, intestinal-FABP and trefoil factor-3 can help neonatologists to differentiate infants with NEC who ultimately require surgery from those with late-onset sepsis or NEC infants who do not require surgery [3]. Though gut-specific proteins are generally considered to be specific for bowel injury, they neither have a high enough sensitivity in the early phase to serve as 'early warning' biomarkers for NEC nor are they able to reliably diagnose the mild cases [3]. In conclusion, many new biomarkers have emerged over the past years. Each category of NEC biomarkers has unique characteristics that render them useful in different phases of the disease. The strengths and limitations of these biomarkers complement each other and underscore the need for further investigation utilising carefully chosen panels for diagnosing and managing NEC infants.

\section{References}

1 Ng PC: Biomarkers of necrotising enterocolitis. Semin Fetal Neonatal Med 2014;19:33-38.

2 Lam HS, Wong SP, Cheung HM, et al: Early diagnosis of intra-abdominal inflammation and sepsis by neutrophil CD64 expression in newborns. Neonatology 2010;99:118-124.

3 Ng EW, Poon TC, Lam HS, et al: Gut-associated biomarkers L-FABP, I-FABP and TFF3, and LIT score for diagnosis of surgical necrotizing enterocolitis in preterm infants. Ann Surg 2013;258:1111-1118.

4 Ng PC, Ang IL, Chiu RW, et al: Host-response biomarkers for diagnosis of late-onset septicemia and necrotizing enterocolitis in preterm infants. J Clin Invest 2010;120:2989-3000.

5 Ng PC, Li K, Leung TF, et al: Early prediction of sepsis-induced disseminated intravascular coagulation with interleukin-10, interleukin-6 and RANTES in preterm infants. Chin Chem 2006;52:1181-1189.

6 Lam HS, Cheung HM, Poon TC, et al: Neutrophil CD64 for daily surveillance of systemic infection and necrotizing enterocolitis in preterm infants. Clin Chem 2013;59:1753-1760.

7 Pourcyrous M, Korones SB, Yang W, et al: C-reactive protein in the diagnosis, management, and prognosis of neonatal necrotizing enterocolitis. Pediatrics 2005;116:1064-1069. 
8 Groselj-Grenc M, Ihan A, Pavcnik-Arnol M, et al: Neutrophil and monocyte CD64 indexes, lipopolysaccharide-binding protein, procalcitonin and C-reactive protein in sepsis of critically ill neonates and children. Intensive Care Med 2009;35:1950-1958.

-9 Benkoe T, Baumann S, Weninger M, et al: Comprehensive evaluation of 11 cytokines in premature infants with surgical necrotizing enterocolitis. PLoS One 2013;8:e58720.

10 Carroll D, Corfield A, Spicer R, Cairns P: Faecal calprotectin concentrations and diagnosis of necrotizing enterocolitis. Lancet 2003;361: 310-311.

11 Zoppelli L, Guttel C, Bittrich HJ, et al: Fecal calprotectin concentrations in premature infants have a lower limit and show postnatal and gestational age dependence. Neonatology 2012;102:68-74.

12 Thuijls G, Derikx JP, van Wijck K, et al: Non-invasive markers for early diagnosis and determination of the severity of necrotizing enterocolitis. Ann Surg 2010;251:1174-1180.

13 Aydemir C, Dilli D, Oguz SS, et al: Serum intestinal fatty acid binding protein level for early diagnosis and prediction of severity of necrotizing enterocolitis. Early Hum Dev 2011;87:659-661.

\section{9}

\section{Breast Milk, Probiotics and Lactoferrin in Newborn Care: What Is the Evidence?}

N. Modi

Section of Neonatal Medicine, Imperial College London, London, UK

Breastfeeding is associated with multiple health benefits and, with few exceptions, breastfeeding is recommended for all babies. However, observational studies are highly susceptible to confounding, hence a causal relationship between breastfeeding and many positive health outcomes remains uncertain. As it would be unethical to randomise infants to breast or formula feeding, innovative stratagems are required to address these uncertainties. One novel approach for improving inferences of causality from observational studies is by comparing cohorts from high-income with low- or middle-income countries, as confounding influences in these respective settings are likely to differ; this approach suggests that breastfeeding results in improved intelligence quotient, but not in lower blood pressure or body mass index [1]. In the PROBIT (Promotion of Breastfeeding Intervention Trial) cluster randomised trial (ISRCTN37687716) involving over 17,000 healthy full-term infants, hospitals were randomised to deliver the BabyFriendly Hospital Initiative to promote and support breastfeeding developed by the World Health Organization and United Nations Children's Fund (experimental group) or to continuation of existing breastfeeding policies (control group) [2]. Exclusive breastfeeding and breastfeeding duration were substantially improved in the experimental group ( 43 vs. 6 and 7.9 vs. $0.6 \%$ were exclusively breastfed at 3 and 6 months, respectively) and infants in this group had less gastrointestinal infection and atopic eczema in infancy [2], and improved cognitive development at age 6.5 years [3]; however, overweight or obesity up to 11.5 years were not reduced [4], nor were effects identified on blood pressure or metabolic indices [5]. This conclusion is in accord with our recent data in which, using a direct measure of adiposity, we found no differences between breastfed and formula-fed infants up to 2 months [6], and a sys- tematic review and meta-analysis of world literature indicating that over the first 6 months, healthy, full-term breastfed infants are more adipose than formula-fed infants [7]. Maternal milk is widely held to reduce the risk of necrotising enterocolitis in preterm babies, however, good evidence is lacking to conclude that there is similar efficacy for pasteurised human donor milk when used as a supplement to maternal milk (risk ratio $1.96,95 \%$ CI $0.82-4.67$ ) [8]. Post hoc analyses of follow-up data from preterm babies recruited to nutritional trials in the early 1980s also suggest positive effects of human milk on intelligence and metabolic markers despite slower growth velocity $[9,10]$. Studies such as these demonstrate the inadvisability of employing growth as an outcome measure in infant nutrition studies, and reinforce the importance of identifying reliable biomarkers of long-term health and the advisability of designing trials to evaluate functional outcomes wherever possible. The international neonatal community has been enthusiastic in researching the use of probiotics in the preterm population. Twenty-four randomised trials are included in a Cochrane systematic review and meta-analysis published in 2014 [11]. Significant reductions are shown in severe necrotising enterocolitis [stage II or more; relative risk (RR) 0.43 , 95\% CI 0.33 0.56; 20 studies, 5,529 infants] and mortality (RR 0.65, 95\% CI $0.52-0.81$; 17 studies, 5,112 infants), but curiously there is no evidence of a significant reduction in sepsis (RR 0.91, 95\% CI 0.80$1.03 ; 19$ studies, 5,338 infants). Reassuringly, there are no reports of systemic infection with the supplemental probiotic, but sadly only 3 trials did not involve the use of formula, and no trial reports any planned assessments of longer-term clinical outcomes or mechanistic evaluations. It is also important to note that results from the largest trial to date, the UK PiPS study (ISRCTN05511098) have yet to be incorporated. To date, trials vary substantially in enrolment criteria, baseline rates of necrotising enterocolitis, probiotic type, time and duration of administration, dose and feeding regimen, and long-term effects on immune function and metabolism that might ensue when a maternally derived intestinal microbiome is replaced with an exogenous strain remain wholly uncertain. For the moment, therefore, attempts to advocate for universal use in preterm babies as a standard of care appear premature. Lactoferrin, a mammalian milk glycoprotein, is another proposed approach to prevent sepsis and necrotising enterocolitis in preterm neonates. A Cochrane meta-analysis indicates that oral lactoferrin prophylaxis reduces the incidence of late-onset sepsis in infants weighing less than $1,500 \mathrm{~g}$, but evidence for a reduction in necrotising enterocolitis is insufficient, as is the efficacy of the combination of lactoferrin with probiotics [12]. The cardinal source of probiotics (to say nothing of prebiotic oligosaccharides, lactoferrin, lysozyme, immunoglobulin and other immunologically active molecules that are to be found in colostrum and breast milk) is a baby's mother. It, therefore, seems not unreasonable to suggest that it would be well for the neonatal community to match enthusiasm for 'off-the-shelf probiotics and other anti-infective therapies with equal enthusiasm for providing maternal colostrum to preterm babies as soon as even a few drops are available, and to follow this with feeds of fresh maternal milk. Remarkably, there is substantial variation in the extent to which preterm neonates receive maternal milk. For example population-based data from England analysed by the Neonatal Data Analysis Unit show a threefold variation in any breastfeeding at discharge among babies born below 30 weeks of gestation, indicating that many neonatal units could achieve much greater breastfeeding success [13]. 
Health care professionals have an obligation to reduce uncertainties in care and to introduce safe, efficacious and effective therapies without delay. Adequately powered, high-quality trials have rightly been embraced with enthusiasm. However, I suggest that in preterm care we also have other major obligations. We need to improve the all too often extraordinarily poor availability of colostrum and maternal milk, especially for the most vulnerable babies. We need to develop mechanisms to ensure that all infants recruited to trials or receiving inadequately evidenced therapies, receive long-term follow-up designed to test specific hypotheses relating to safety, later outcomes and biological effector mechanisms. We need to promote basic science research in newborn medicine to understand causal pathways as enthusiastically as we have embraced randomised controlled trials. Not least, I look forward to a day when the regulatory environment facilitates the conduct of international trials of promising new therapies, as well as comparative effectiveness research of treatments already in wide use, much more readily, rapidly and rationally than is presently the case [14].

\section{References}

1 Brion MJ, Lawlor DA, Matijasevich A, et al: What are the causal effects of breastfeeding on IQ, obesity and blood pressure? Evidence from comparing high-income with middle-income cohorts. Int J Epidemiol 2011; 40:670-680.

-2 Kramer MS, Chalmers B, Hodnett ED, et al: Promotion of Breastfeeding Intervention Trial (PROBIT): a randomized trial in the Republic of Belarus. JAMA 2001;285:413-420.

-3 Kramer MS, Aboud F, Mironova E, et al: Breastfeeding and child cognitive development: new evidence from a large randomized trial. Arch Gen Psychiatry 2008;65:578-584.

4 Martin RM, Patel R, Kramer MS, et al: Effects of promoting longer-term and exclusive breastfeeding on adiposity and insulin-like growth factorI at age 11.5 years: a randomized trial. JAMA 2013;309:1005-1013.

5 Martin RM, Patel R, Kramer MS, et al: Effects of promoting longer-term and exclusive breastfeeding on cardiometabolic risk factors at age 11.5 years: a cluster-randomized, controlled trial. Circulation 2014;129:321329.

-6 Gale C, Thomas EL, Jeffries S, et al: Adiposity and hepatic lipid in healthy full-term, breastfed, and formula-fed human infants: a prospective shortterm longitudinal cohort study. Am J Clin Nutr 2014;99:1034-1040.

7 Gale C, Logan KM, Santhakumaran S, et al: Effect of breastfeeding compared with formula feeding on infant body composition: a systematic review and meta-analysis Am J Clin Nutr 2012;95:656-669.

8 Quigley M, McGuire W: Formula versus donor breast milk for feeding preterm or low birth weight infants. Cochrane Database Syst Rev 2014; 4:CD002971.

9 Isaacs EB, Fischl BR, Quinn BT, et al: Impact of breast milk on intelligence quotient, brain size, and white matter development. Pediatr Res 2010;67:357-362.

10 Singhal A, Lucas A: Early origins of cardiovascular disease: is there a unifying hypothesis? Lancet 2004;363:1642-1645.

11 Alfaleh K, Anabrees J: Probiotics for prevention of necrotizing enterocolitis in preterm infants. Cochrane Database Syst Rev 2014;4:CD005496.

12 Pammi M, Abrams SA: Oral lactoferrin for the prevention of sepsis and necrotizing enterocolitis in preterm infants. Cochrane Database Syst Rev 2011;10:CD007137.

13 Annual report of the Chief Medical Officer 2012: Our children deserve better: prevention. pays.https://www.gov.uk/government/uploads/system/uploads/attachment_data/file/255237/2901304_CMO_complete_ low_res_accessible.pdf (last accessed 07/05/14)

14 Modi N: How not to reduce uncertainties in care. BMJ 2013;346:\{3786.

\section{0 \\ Diagnosis and Management of Hypotension in the Preterm Infant}

E.M. Dempsey ${ }^{a, b}$

aDepartment of Paediatrics and Child Health and ' Infant Centre, University College Cork, Cork, Ireland

A very large proportion of preterm infants continue to receive intervention for hypotension in the immediate transitional period. A number of national and international surveys [1-3] highlight the continued reliance on mean blood pressure values to guide intervention, despite a lack of good quality evidence to support this intervention criterion [4]. Numerous normative blood pressure reference ranges exist, but these ranges are remarkable only by their significant variability [5-7]. One common definition is a mean blood pressure $<30 \mathrm{~mm} \mathrm{Hg}$, which is physiologically implausible across such wide gestational age ranges [8]. A blood pressurebased approach to the diagnosis and management of hypotension is the current standard, primarily because of historical precedence and the fact these values are readily available at the bedside, either continuously or intermittently, and the effects of an intervention can be easily evaluated. Other parameters of cardiovascular wellbeing are not so readily available or necessarily as reproducible at the bedside. These include clinical evaluation (heart rate, capillary refill, colour and level of activity), point-of-care biochemical parameters (base deficit and lactate), point-of-care functional echocardiography, near-infrared spectroscopy and more recently methods of non-invasive cardiac output monitoring. Each of these methods have their own inherent limitations, but it is probable that these forms of assessment in conjunction with blood pressure values will provide a better global assessment of circulatory well-being than blood pressure values alone $[9,10]$. The general assumption is that a low blood pressure equates to low blood flow and hence the risk of both short-and long-term adverse outcomes in preterm infants with limited capacity for cerebral autoregulation [11]. However, the relationship between low blood pressure and adverse outcome is not consistent [12-14]. A number of studies have documented a worse outcome in preterm infants with low blood pressure, and undoubtedly the lower the mean blood pressure, the greater the risk of an adverse outcome. Data from the Canadian Neonatal Network highlighted a worse outcome in extremely preterm infants when the mean blood pressure was $<20$ $\mathrm{mm} \mathrm{Hg}$ and even more so when the mean blood pressure was $<15$ $\mathrm{mm} \mathrm{Hg}$ [15]. More recently, Batton et al. [16] examined 15 different definitions of hypotension in a large cohort of extremely low gestational age preterm infants and were unable to identify a relationship between any of the definitions chosen and adverse outcome. The contrasting findings from these studies are not surprising as the definitions of low blood pressure varied from study to study, and blood pressure alone may be a poor surrogate marker of end organ perfusion [17]. The only consistent finding from the surveys of practice to date is that a mean blood pressure less than gestational age is the most common criterion used to initiate intervention, and that the most common intervention is volume administration followed by dopamine therapy $[1,2]$. Dopamine has been in use in newborn care for almost 40 years, is one of the most studied agents in this population of infants and has been the subject of 19 randomised controlled trials to date. However, despite numerous studies in this area, none have been adequately powered 
to address clinically relevant end points, namely death, ultrasound abnormality or long-term neurodevelopmental outcome in this vulnerable group of infants. A recent feasibility study highlighted some of the potential problems in conducting such trials [18]. Despite identifying 119 extremely low gestational age newborns with low blood pressure, only 10 patients were ultimately enrolled. Difficulties included lack of clinician equipoise and refusal of parental consent. Despite these difficulties, the problem still remains and needs to be answered. The ultimate goal in the management of newborn hypotension should be to maintain or restore effective tissue perfusion and this should be assessed on a continual basis by monitoring a combination of clinical, biochemical and haemodynamic parameters. A number of important trials in this area are now underway, comparing different definitions of hypotension and different interventions. These include (1) TOHOP (Treatment of Hypotension of Prematurity); (2) HIP (Hypotension in the Preterm Infant) [19], and (3) NEOCIRC (Neocirculation). It is hoped that these trials will provide clinicians with a greater understanding of the diagnosis and treatment of hypotension in the preterm infant during neonatal transition.

\section{References}

1 Sehgal A, Osborn D, McNamara PJ: Cardiovascular support in preterm infants: a survey of practices in Australia and New Zealand. J Paediatr Child Health 2012;48:317-323.

-2 Stranak Z, Semberova J, Barrington K, et al: International survey on diagnosis and management of hypotension in extremely preterm babies. Eur J Pediatr 2014;173:793-798.

3 Dempsey EM, Barrington KJ: Diagnostic criteria and therapeutic interventions for the hypotensive very low birth weight infant. J Perinatol 2006;26:677-681.

4 Dempsey EM, Barrington KJ: Treating hypotension in the preterm infant: when and with what: a critical and systematic review. J Perinatol 2007;27:469-478.

5 Development of audit measures and guidelines for good practice in the management of neonatal respiratory distress syndrome. Report of a Joint Working Group of the British Association of Perinatal Medicine and the Research Unit of the Royal College of Physicians. Arch Dis Child 1992; 67(10 Spec No):1221-1227.

6 Hegyi T, Carbone MT, Anwar M, et al: Blood pressure ranges in premature infants. I. The first hours of life. J Pediatr 1994;124:627-633.

7 Watkins AM, West CR, Cooke RW: Blood pressure and cerebral haemorrhage and ischaemia in very low birthweight infants. Early Hum Dev 1989; 19:103-110.

$>8$ Bada HS, Korones SB, Perry EH, et al: Mean arterial blood pressure changes in premature infants and those at risk for intraventricular hemorrhage. J Pediatr 1990;117:607-614.

-9 Dempsey EM, Al Hazzani F, Barrington KJ: Permissive hypotension in the extremely low birthweight infant with signs of good perfusion. Arch Dis Child Fetal Neonatal Ed 2009;94:F241-F244.

10 Pellicer A, Greisen G, Benders M, et al: The SafeBoosC phase II randomised clinical trial: a treatment guideline for targeted near-infraredderived cerebral tissue oxygenation versus standard treatment in extremely preterm infants. Neonatology 2013;104:171-178.

11 Tsuji M, Saul JP, du Plessis A, et al: Cerebral intravascular oxygenation correlates with mean arterial pressure in critically ill premature infants. Pediatrics 2000;106:625-632.

12 Fanaroff AA, Fanaroff JM: Short- and long-term consequences of hypotension in ELBW infants. Semin Perinatol 2006;30:151-155.

13 Seri I: Low superior vena cava flow during the first postnatal day and neurodevelopment in preterm neonates. J Pediatr 2004;145:573-575.

14 Cunningham S, Symon AG, Elton RA, et al: Intra-arterial blood pressure reference ranges, death and morbidity in very low birthweight infants during the first seven days of life. Early Hum Dev 1999;56:151-165.
15 Barrington KJ, Lee SK, Stewart S, Canadian Neonatal Network: Differing blood pressure thresholds in preterm infants, effects on frequency of diagnosis of hypotension and intraventricular hemorrhage. Pediatr Res 2002;51:455A.

16 Batton B, Li L, Newman NS, et al: Use of antihypotensive therapies in extremely preterm infants. Pediatrics 2013;131:e1865-e1873.

17 Groves AM, Kuschel CA, Knight DB, Skinner JR: Relationship between blood pressure and blood flow in newborn preterm infants. Arch Dis Child Fetal Neonatal Ed 2008;93:F29-F32.

18 Batton BJ, Li L, Newman NS, et al: Feasibility study of early blood pressure management in extremely preterm infants. J Pediatr 2012;161:65. e1-69.e1.

19 Dempsey EM, Barrington KJ, Marlow N, et al: Management of hypotension in preterm infants (The HIP Trial): a randomised controlled trial of hypotension management in extremely low gestational age newborns. Neonatology 2014;105:275-281.

\section{1 \\ Caffeine and Inhaled Steroids in the Very Preterm Infant: Time for Prophylaxis?}

\section{Bassler}

\section{Division of Neonatology, University Hospital Zurich, Zurich, Switzerland}

Pediatric off-label drug use in hospitals remains very common [1]. Among pediatric patients, the percentage of unlicensed and off-label drug use is highest in neonates [1]. Thus, high-quality neonatal clinical drug trials with sufficient sample sizes to allow firm conclusions are needed, not only for the investigation of new and future drugs but also for old products that are widely used in clinical practice without sufficient data on efficacy and safety, such as inhaled steroids for the prevention and/or treatment of bronchopulmonary dysplasia (BPD), for example [2]. Another example of a drug that has been used for more than 40 years and until 2006 was one of the most commonly prescribed drugs in neonatal medicine, with only a few relatively small and short-term studies supporting its use, is caffeine, a methylxanthine and nonspecific inhibitor of adenosine receptors. It is thanks to the efforts of Barbara Schmidt and the Caffeine for Apnea of Prematurity (CAP) Trial Group that we now have high-quality and reliable data not only on the short-term but also on the long-term outcomes of caffeine use for apnea of prematurity [3-5]. CAP is an international, multicenter, placebo-controlled randomized trial that was designed to determine whether survival without neurodevelopmental disability at a corrected age of 18 months is improved if apnea of prematurity is managed without methylxanthines in infants at high risk of apneic attacks [3]. Infants with birth weights of 500$1,250 \mathrm{~g}$ were enrolled during the first 10 days of life if their clinicians considered them to be candidates for methylxanthine therapy [3]. The most frequent indication for therapy reported in CAP was treatment of documented apnea, followed by the facilitation of endotracheal tube removal [6]. Only about $20 \%$ of the neonatologists in the trial started caffeine for the prevention of apnea [6]. Thus, the findings of CAP should not automatically be extrapolated to an exclusive prophylactic indication and time for prophylaxis has not come. However, in a recent cross-sectional survey of all neonatologists in Thailand, Lebanon, Australia and a represen- 
tative sample in the USA regarding the management of apnea of prematurity with a response rate of $50 \%$, prophylactic methylxanthine use was very common (62\%) among neonatologists in all four study locations [7]. The answer to the question whether the time for routine prophylaxis has come for inhaled steroids for the prevention of BPD based on the currently published evidence is 'no'. Nevertheless, a recent survey among pediatricians in chief of all the 343 German pediatric hospitals with a neonatal unit (all levels of neonatal care) indicated that $46 \%$ of the responders administered inhaled corticosteroids to premature infants either as prophylaxis or treatment for BPD [2]. The current systematic review from the Cochrane Collaboration focusing on the early administration of inhaled steroids for the prevention of BPD includes seven randomized controlled trials [8]. This review found no statistically significant effect of inhaled steroids on BPD either at 28 days [typical relative risk 1.05 (95\% CI 0.84-1.32); typical risk difference $0.02(95 \%$ CI $-0.07-0.11)$ ] or at 36 weeks postmenstrual age [typical relative risk 0.97 (95\% CI 0.62-1.52); typical risk difference 0.00 ( $95 \%$ CI -0.07 to 0.06$)$ ] when data were analyzed either for all randomized infants or only for survivors [8]. No statistically significant differences were noted for mortality or for the combined outcome of mortality and BPD either at 28 days of age or at 36 weeks postmenstrual age. The review identified no statistically significant differences in adverse events between the groups [8]. The authors of this systematic review conclude that 'there is no evidence from the trials reviewed that early administration (in the first two weeks of life) of inhaled steroids to ventilated preterm neonates is effective in reducing the incidence of CLD. Currently, use of inhaled steroids in this population cannot be recommended. Studies are needed to identify the risk/benefit ratio of different delivery techniques and dosing schedules for the administration of these medications. Studies need to address both the short-term and long-term benefits and adverse effects of inhaled steroids with particular attention to neurodevelopmental outcome' [8]. One study that aims at answering the question whether the early (within $12 \mathrm{~h}$ of life) prophylactic use of inhaled corticosteroids (budesonide) in very preterm infants (gestational age 23 0/7-27 6/7 weeks) requiring any form of positive pressure support (mechanical or nasal ventilation or continuous positive airway pressure) increases survival without BPD at 36 weeks of gestational age and also assesses longterm neurodevelopmental outcomes in NEUROSIS (Neonatal European Study of Inhaled Steroids) [9], a randomized placebo-controlled, international clinical trial. Enrollment of approximately 850 infants has finished and results of the study are expected soon.

\section{References}

$\checkmark 1$ Kimland E, Nydert P, Odlind V, et al: Paediatric drug use with focus on off-label prescriptions at Swedish hospitals - a nationwide study. Acta Paediatr 2012;101:772-778.

2 Maas C, Poets CF, Bassler D: Survey of practices regarding utilization of inhaled steroids in 223 German neonatal units. Neonatology 2010;98: 404-408.

>3 Schmidt B, Roberts RS, Davis P, Doyle LW, Barrington KJ, Ohlsson A, Solimano A, Tin W; Caffeine for Apnea of Prematurity Trial Group: Caffeine therapy for apnea of prematurity. N Engl J Med 2006;354:21122121.

-4 Schmidt B, Roberts RS, Davis P, Doyle LW, Barrington KJ, Ohlsson A, Solimano A, Tin W; Caffeine for Apnea of Prematurity Trial Group: Long-term effects of caffeine therapy for apnea of prematurity. N Engl J Med 2007;357:1893-1902.
5 Schmidt B, Anderson PJ, Doyle LW, Dewey D, Grunau RE, Asztalos EV, Davis PG, Tin W, Moddemann D, Solimano A, Ohlsson A, Barrington KJ, Roberts RS; Caffeine for Apnea of Prematurity (CAP) Trial Investigators: Survival without disability to age 5 years after neonatal caffeine therapy for apnea of prematurity. JAMA 2012;307:275-282.

-6 Davis PG, Schmidt B, Roberts RS, Doyle LW, Asztalos E, Haslam R, Sinha S, Tin W; Caffeine for Apnea of Prematurity Trial Group: Caffeine for Apnea of Prematurity trial: benefits may vary in subgroups. J Pediatr 2010;156:382-387.

7 Abu Jawdeh EG, O’Riordan M, Limrungsikul A, et al: Methylxanthine use for apnea of prematurity among an international cohort of neonatologists. J Neonatal Perinatal Med 2013;6:251-256.

8 Shah VS, Ohlsson A, Halliday HL, Dunn M: Early administration of inhaled corticosteroids for preventing chronic lung disease in ventilated very low birth weight preterm neonates. Cochrane Database Syst Rev 2012;5:CD001969.

9 Bassler D, Halliday HL, Plavka R, et al: The Neonatal European Study of Inhaled Steroids (NEUROSIS): an EU-funded international randomised controlled trial in preterm infants. Neonatology 2010;97:52-55.

\section{2}

\section{Useless and Dangerous Therapies in Neonatology}

H.L. Halliday

Department of Child Health, Queen's University Belfast,

Belfast, UK

The term neonatology has been in existence for about 50 years but expert care of the newborn extends much further back in time [1]. In this review, I will discuss some useless or harmful therapies used in neonatal medicine in the past 200 years. I have drawn on experience and writings of four eminent neonatologists: Bill Silverman [2-4], Alex Robertson [5-7], Alistair Philip [8, 9] and Michael Obladen [10-12]. Early History - Congenital Syphilis, Thrush and Wet Nursing: In 1780, a specialised infant hospital was founded in Vaugirard to treat infants with congenital syphilis with mercury administered by nurses' milk [12]. Seventy-nine percent of 1,864 treated infants died but $19 \%(\mathrm{n}=349)$ were discharged as 'healed'. Foundling hospitals in the 18th century admitted thousands of newborns each year and less than a third survived their 1 st year [10]. These foundlings died from infections, often venereal in origin, but also acquired because of overcrowding and poor sanitation. Thrush or oral candidiasis was rife and probably transmitted by use of wet nurses. Local treatments for thrush included abrasion, astringents, boric acid, vitriol or alum. Effective treatment with nystatin (named after the New York State Department of Health where it was developed) was not available until the 1950s. Wet nursing has been practised from antiquity, availed of by the wealthy and a ready source of income for the poor [11]. It existed only because the wet nurse's baby had either died or was given to a foundling hospital. 1930s and 1940s - Uncontrolled Oxygen, Inappropriate Thermal Care and Withholding Feeds: Although oxygen had been used earlier to treat apnea and perinatal asphyxia, Bill Silverman said that 'the modern era of treatment (routine prolonged exposure of small premature infants to high concentrations of oxygen) began in earnest... in 1942' [1, 4]. In 1951 the link between uncontrolled oxygen supplementation and retrolental fibroplasia, now known as retinopathy of prematurity, was first recognised. The Cooperative Study (1955) was interpreted as showing 
that $<40 \%$ oxygen was safe for preterm infants. It took another 5 years to discover this was flawed and the reduction to $<40 \%$ was said to have increased mortality of infants with the respiratory distress syndrome and cerebral palsy in survivors [1]. Even today, uncertainty remains about safe targets for oxygenation of very preterm infants [13]. Similarly, flawed interpretation of research studies allowed preterm babies to be nursed in 'subnormal temperatures' as it was 'believed to be a characteristic of prematurity' [1]. A randomised controlled trial by Bill Silverman in 1959 showed much better survival of infants in incubators at $32^{\circ} \mathrm{C}$ compared to $29^{\circ} \mathrm{C}$ and 'it is impossible to know how many babies died from inappropriate environmental temperature during the approximately 50 years before newborn temperature control was understood' $[1,5]$. Fear of aspiration led to the practice of withholding feeds for $72 \mathrm{~h}$ in preterm infants [1]. From the 1960s, there were concerns that delayed feeding was associated with an increased risk of neurodevelopmental problems and cerebral palsy, which may have been due to hypoglycemia and hyperbilirubinemia. Even today, undernutrition of preterm infants may persist although 'remarkable improvements in mortality over the last 50 years are mostly attributable to adequate nutrition, appropriate temperature control, antibiotics and ventilation methods' [5]. 1950s and 1960s - Chloramphenicol, Hexachlorophene and Epsom Salt Enemas: Chloramphenicol was given prophylactically to newborns at risk of infection in the 1950s but mortality in preterm infants increased from 29 to 144 per 1,000 after its introduction for preterm rupture of the membranes [1]. Over $10 \%$ of infants treated with chloramphenicol died of 'grey baby syndrome', which typically developed a few days after starting treatment. After reducing the dose from $100-150$ to $20-50 \mathrm{mg} / \mathrm{kg} /$ day, about 1,960 cases of grey baby syndrome disappeared [6]. Toxicity was due to impaired glucuronidation and reduced renal excretion allowing the drug to accumulate. Another drug with toxic effects was hexachlorophene used as a $3 \%$ solution to bathe infants to prevent staphylococcal skin colonisation [6]. Neurotoxicity was first reported in 1959 about 7 years after its introduction, and in 1971 the American Academy of Pediatrics recommended an end to hexachlorophene baths. In 1964, Epsom salt enemas were reported to be $100 \%$ effective in the treatment of the respiratory distress syndrome on the basis of a consecutive series of 28 preterm babies [2]. Magnesium toxicity also occurred with at least 1 neonatal death but as sporadic use continued until the mid-1970s, there 'is no way of knowing how many babies died as a result of its use' [6]. Sodium Bicarbonate, Benzyl Alcohol as an Excipient and BPD with Steroids: Sodium bicarbonate has been used for a long time to treat neonatal cardiac arrest and metabolic acidosis with standard practice being correction of acidosis before giving epinephrine during cardiopulmonary resuscitation [14]. Doubts about bicarbonate therapy were first raised in the 1980s when animal studies showed detrimental effects on myocardial function and reduced likelihood of successful resuscitation. There are no studies in neonates showing either short- or long-term benefits of sodium bicarbonate after cardiac arrest [14]. There is also insufficient evidence that infusions of sodium bicarbonate reduce morbidity or mortality of preterm infants with metabolic acidosis. Thus, bicarbonate is 'basically a useless therapy' [14]. Benzyl alcohol used as an excipient may be more than useless as severe metabolic acidosis, renal and hepatic failure with neurologic signs and gasping respiration occurred in some preterm infants given saline flushes containing $0.9 \%$ benzyl alcohol [1]. In 1982, the Food and Drug Administration recommend- ed that flush solutions should no longer contain benzyl alcohol or any other preservatives, and the gasping syndrome disappeared. BPD has been a major concern in neonatology since the late 1960s [9]. High oxygen concentrations and peak inspiratory pressures were implicated in causation of 'classical BPD' and 'new BPD' began to replace it after introduction of surfactant treatment in the 1990s [9]. Of many therapies introduced to treat or prevent BPD, corticosteroids are probably the most notorious [1]. Dexamethasone was first used in the late 1970s to treat severe BPD and 2 early studies suggested short-term benefits in ventilator-dependent infants when very large doses were given $(0.5 \mathrm{mg} / \mathrm{kg} / \mathrm{day})$. Soon, further trials of dexamethasone to prevent BPD in preterm infants were performed and by the late 1990 s over 4,000 had been enrolled in randomised controlled trials [1]. Once long-term outcomes had been assessed after 1998, it became clear that treatment with dexamethasone in the 1st week was associated with a $75 \%$ increased risk of cerebral palsy $[1,15]$. Thus, dexamethasone has good short-term benefits but adverse long-term effects if given soon after birth in relatively high doses. Whether lower doses or other steroid drugs, including inhaled drugs, used after 7 days when BPD is evolving, are effective and safe remains to be confirmed [1]. Conclusion: Introduction of new therapies into neonatal medicine should be based upon the results of large randomised controlled trials with appropriate long-term outcomes in infancy, if not childhood [1].

\section{References}

1 Halliday HL: Useless perinatal therapies. Neonatology 2010;97:358-365.

2 Silverman WA: Retrolental Fibroplasia. A Modern Parable. New York, Grune \& Stratton, 1980.

3 Silverman WA: The schizophrenic career of a 'monster drug'. Pediatrics 2002;110:404-406.

-4 Silverman WA: A cautionary tale about supplemental oxygen: the albatross of neonatal medicine. Pediatrics 2004;113:394-396.

5 Robertson AF: Reflections on errors in neonatology. I. The 'hands-off years' 1920 to 1950 . J Perinatol 2003;23:48-55.

-6 Robertson AF: Reflections on errors in neonatology. II. The 'heroic years' 1950 to 1970. J Perinatol 2003;23:154-161.

7 Robertson AF: Reflections on errors in neonatology. III. The 'experienced years' 1970 to 2000 . J Perinatol 2003;23:240-249.

8 Philip AGS: The evolution of neonatology. Pediatr Res 2005;58:799-815.

9 Philip AGS: Bronchopulmonary dysplasia: then and now. Neonatology 2012;102:1-8.

10 Obladen M: Thrush - nightmare of the foundling hospitals. Neonatology 2012;101:159-165.

11 Obladen M: Regulated wet nursing: managed care or unrecognized crime? Neonatology 2012;102:222-228.

12 Obladen M: Curse of two generations: a history of congenital syphilis. Neonatology 2013;103:274-280.

13 Saugstad OD, Aune D: Optimal oxygenation of extremely low birth weight infants: a meta-analysis and systematic review of the oxygen saturation target studies. Neonatology 2014;105:55-63.

14 Aschner JL, Poland RL: Sodium bicarbonate: basically useless therapy. Pediatrics 2008;122:831-835.

15 Doyle LW, Ehrenkranz RA, Halliday HL: Dexamethasone treatment in the first week of life for preventing bronchopulmonary dysplasia: a systematic review. Neonatology 2010;98:217-224. 


\section{3}

\section{Can Brain Cooling Be Optimized by Xenon or Other Interventions?}

D. Azzopardi

Centre for the Developing Brain, King's College London, London, UK

Perinatal asphyxia severe enough to cause moderate-to-severe encephalopathy occurs in about 1-2/1,000 births in resource-rich countries with a more than 10 -fold greater rate in countries with limited resources [1]. There is a high risk of death and cerebral injury in survivors. It is an important public health problem globally, has large opportunity costs for the affected families and health services, and leads to major litigation claims. Moderate hypothermia is the first therapeutic intervention shown to improve neurological outcomes following perinatal asphyxia [2]. It has been endorsed by professional organisations and rapidly became the standard of care in several high- and mid-resource countries [3], but its role in resource-poor countries still needs to be elucidated [4]. Moderate hypothermia improved clinical outcomes in adults following out-of-hospital cardiac arrest and continues to be investigated for neuroprotective treatment after stroke and head injuries. However, the efficacy of moderate hypothermia following cardiac arrest in adults has recently been questioned after a large study found no significant differences in survival and short-term neurological outcomes in unconscious individuals with presumed cardiac cause treated at a core temperature of 36 or $33^{\circ} \mathrm{C}$ [5]. Several high-quality randomised controlled trials confirmed that moderate hypothermia after perinatal asphyxia improves neurological outcome in early childhood (up to 2 years of age), but data are scarce about longer-term outcomes. Until recently, two studies have reported results in middle childhood: the CoolCap study of selective head cooling reported parental questionnaire data from $62 / 135(46 \%)$ survivors at $7-8$ years and so was underpowered to examine the effect of hypothermia on cognitive function at higher age [6]. The Childhood Outcomes after Hypothermia for Neonatal Encephalopathy study (NICHD study) achieved a high follow-up rate at 6-7 years, and reported lower mortality in the hypothermia group compared with the control group, but no significant differences in rates of disability or cognitive outcomes, probably due to lack of power [7]. Whilst waiting for the data from the largest trial of moderate hypothermia after perinatal asphyxia, the TOBY trial of moderate whole-body hypothermia, the lack of conclusive clinical trial evidence of continuing neurological benefit after therapeutic hypothermia raised doubt as to whether there are long-term benefits of intervention after perinatal asphyxia. The TOBY Children study will shortly report outcomes of 280 (86\%) participants at 6-7 years of age in the TOBY trial. It found that children allocated hypothermia were significantly more likely to survive with an IQ $\geq 85$, and the rates of cerebral palsy and moderate/severe disabilities were reduced in survivors, but the rate of death was similar in the hypothermia and control groups. Combining the results of the TOBY and NICHD studies confirms that moderate hypothermia results in improved outcomes in middle childhood. Following perinatal asphyxia despite treatment with hypothermia, the rates of death $(\sim 29 \%)$, cerebral palsy $(\sim 23 \%)$ and cognitive deficiency $(\sim 35 \%)$ in survivors remain high so additional therapies are needed, and several therapies targeting known pathophysiological pathways involved after perinatal asphyxia are under study [8]. Since large clinical trials will be needed to confirm efficacy, it is essential that robust preclinical and early clinical data underpin the development of new therapies. One promising additional therapy is xenon. Xenon, a monoatomic gas with high tissue solubility, may be neuroprotective following asphyxia through different mechanisms: it is a non-competitive inhibitor of the NMDA subtype of the glutamate receptor and reduces apoptosis probably by up-regulating hypoxia-inducible factor-1a protein and in turn erythropoietin. Experimentally, it reduces cerebral injury in models of hypoxic ischemic injury in different animal species and the neuroprotective effect is stronger when xenon is combined with moderate hypothermia $[9,10]$. Preliminary clinical studies suggest that ventilation with $30-50 \%$ xenon gas for 18 $24 \mathrm{~h}$ combined with moderate hypothermia in encephalopathic newborns is feasible and appears safe. A preliminary report from the first randomised trial in newborns (TOBY Xe trial) reported that $30 \%$ xenon reduces seizures, though seizures recurred transiently when xenon was discontinued [11]. This trial will complete at the end of 2014 and the results of the early outcomes expected soon after.

\section{References}

1 Lawn JE, Cousens S, Zupan J, Lancet Neonatal Survival Steering Team: 4 million neonatal deaths: when? Where? Why? Lancet 2005;365:891900.

- 2 Jacobs SE, Berg M, Hunt R, Tarnow-Mordi WO, Inder TE, Davis PG: Cooling for newborns with hypoxic ischaemic encephalopathy. Cochrane Database Syst Rev 2013;1:CD003311.

3 Therapeutic hypothermia with intracorporeal temperature monitoring for hypoxic perinatal brain injury. 2010. http://www.nice.org.uk/nicemedia/live/11315/48809/48809.pdf (accessed 1/2/2014).

4 Thayyil S, Bhutta ZA, Ramji S, Costello AM, Robertson NJ: Global application of therapeutic hypothermia to treat perinatal asphyxial encephalopathy. Int Health 2010;2:79-81.

5 Nielsen N, Wetterslev J, Friberg H, TTM Trial Steering Group: Targeted temperature management after cardiac arrest. N Engl J Med 2014;370: 1360.

6 Guillet R, Edwards AD, Thoresen M, et al: Seven- to eight-year follow-up of the CoolCap trial of head cooling for neonatal encephalopathy. Pediatr Res 2012;71:205-209.

7 Shankaran S, Pappas A, McDonald SA, et al: Childhood outcomes after hypothermia for neonatal encephalopathy. N Engl J Med 2012;366: 2085-2092.

8 Juul SE, Ferriero DM: Pharmacologic neuroprotective strategies in neonatal brain injury. Clin Perinatol 2014;41:119-131.

-9 Faulkner S, Bainbridge A, Kato T, et al: Xenon augmented hypothermia reduces early lactate/ $\mathrm{N}$-acetylaspartate and cell death in perinatal asphyxia. Ann Neurol 2011;70:133-150.

10 Chakkarapani E, Dingley J, Liu X, et al: Xenon enhances hypothermic neuroprotection in asphyxiated newborn pigs. Ann Neurol 2010;68:330341.

11 Azzopardi D, Robertson NJ, Kapetanakis A, et al: Anticonvulsant effect of xenon on neonatal asphyxial seizures. Arch Dis Child Fetal Neonatal Ed 2013;98:F437-F439. 


\section{4}

\section{Early and Late Complications of Germinal Matrix- Intraventricular Haemorrhage in the Preterm Infant: What Is New?}

\section{A.J. Brouwer, F. Groenendaal, M.J.N.L. Benders, L.S. de Vries}

Department of Neonatology, Wilhelmina Children's Hospital, University Medical Centre Utrecht, Utrecht, The Netherlands

Germinal matrix-intraventricular haemorrhage (GMH-IVH) remains a serious problem in the very and extremely preterm infant. The complete article reviews current methods of diagnosis, treatment and neurodevelopmental outcome in preterm infants with low-grade and severe GMH-IVH. Conclusion: There is still no consensus on timing of intervention and treatment of infants with GMH-IVH, whether or not complicated by post-haemorrhagic ventricular dilatation. The discrepancies between the studies underline the need for international collaboration to define the optimal strategy for these infants.

The complete review will be published in Neonatology, vol. 106, no. $4,2014$.

\section{5 \\ Insulin-Like Growth Factor-1 and Anti-Vascular Endothelial Growth Factor in Retinopathy of Prematurity: Has the Time Come?}

\author{
A. Stahla ${ }^{\text {, A. Hellstrom }}{ }^{b}$, L.E.H. Smith ${ }^{c}$ \\ ${ }^{a} E y e$ Center, University of Freiburg, Freiburg, Germany; \\ ${ }^{b}$ Department of Ophthalmology, Institute of Neuroscience \\ and Physiology, The Sahlgrenska Academy, University \\ of Gothenburg, Gothenburg, Sweden; 'Department of \\ Ophthalmology, Boston Children's Hospital, Harvard Medical \\ School, Boston, Mass., USA
}

See review, pp. 254-260.

\section{6 \\ The Doctor's Dilemma: Serial Biomarkers in the Accurate Diagnosis of Early-Onset Sepsis}

\section{E.J. Molloy}

Department of Paediatrics, Trinity College Dublin, Department of Neonatology, Our Lady's Children's Hospital, and Department of Paediatrics, Royal College of Surgeons in Ireland, Dublin, Ireland

Early-onset sepsis (EOS) is associated with high global costs and a major cause of neonatal mortality and morbidity. In addition, sepsis is associated with adverse neurodevelopmental outcomes especially in preterm infants. Many factors make the diagnosis of EOS challenging, including maternal antenatal antibiotic use and the small volumes of blood for culture [1]. Less than $1 \%$ of newborns have blood culture-proven EOS [2] and signs of clinical sepsis are non-specific. Most clinicians commence treatment while awaiting culture results due to the hazard of untreated sepsis, which can be rapidly progressive and which can increase morbidity and mortality. The use of antibiotics is potentially harmful, especially in preterm infants with a higher risk of drug toxicity due to hepatic and renal immaturity and an increase in antibiotic resistance. The difficulty with newborns is that their in utero infection status is often unknown at birth. Some information can be gleaned from the placental histology and degree of maternal and fetal inflammatory responses but is not available immediately. The relative 'dose and duration' of exposure to infection differs in each case but is difficult to quantify. Recently, lipopolysaccharides have been measured in cord blood from term and preterm infants, and in the former have been found to be markedly elevated irrespective of the mode of delivery [3]. If a baby passed through an infected birth canal the time taken for the pathogen to reach the bloodstream and allow detection by blood culture or PCR is unknown. Newer techniques for bacterial identification such as PCR or dsRNA may aid in the accurate diagnosis of EOS but are not used in routine practice. Surrogate inflammatory markers such as white blood cell count, immature-mature neutrophil ratio, C-reactive protein and calcitonin are often used in clinical practice to aid decision making in newborns at risk of sepsis. Serial measurements of these markers have a higher positive predictive value for EOS than a single measurement. Serial Creactive protein measurements have been validated in EOS especially including a measurement at $>18 \mathrm{~h}$ of age. Mikhael et al. [4] recently demonstrated that serial neutrophil counts over 24 h have high specificity and negative predictive value in term and preterm neonates $(n=2,073)$. They suggest using these measures with 2 blood cultures to allow early cessation of antibiotics resulting in savings in cost and fungal infection. These neutrophil counts and other published studies have used manual differential counts; in the future, use of computer-generated differential counts using flow cytometry may be useful. However, current automated granulocyte norms are inappropriate for evaluating EOS in newborns and need larger studies for validation [5]. George Bernard Shaw's play written in 1908, The Doctors' Dilemma, explores the issues of private medical practice, equality of health care delivery and high-risk therapies and advocate evidence-based practice [6]. The play highlights the doctors' dilemma in treating infection and selecting the correct treatment without overutilising scarce resources. Routine use of serial biomarkers may reduce this dilemma by minimizing antibiotic exposure but ensuring adequate antimicrobial cover for those infants at risk.

\section{References}

1 Schelonka RL, McCracken G: Bacterial and fungal infections; in Avery GB, MacDonald MG, Seshia MMK, Mullett MD (eds): Avery's Neonatology: Pathophysiology and Management of the Newborn, ed 6. Philadelphia, Lippincott Williams \& Wilkins, 2005, pp 1235-1273.

2 Escobar GJ: The neonatal 'sepsis work-up': personal reflections on the development of an evidence-based approach toward newborn infections in a managed care organization. Pediatrics 1999;103:360-373.

-3 Martinez-Lopez DG, Funderburg NT, Cerissi A, et al: Lipopolysaccharide and soluble CD14 in cord blood plasma are associated with prematurity and chorioamnionitis. Pediatr Res 2014;75:67-74.

-4 Mikhael M, Brown S, Rosenfeld CR: Serial neutrophil values facilitate predicting the absence of neonatal early-onset sepsis. J Pediatr 2014;164: $522-528$. 
5 Wiland EL, Sandhaus LM, Georgievskaya Z, et al: Adult and child automated immature granulocyte norms are inappropriate for evaluating early-onset sepsis in newborns. Acta Paediatr 2014;103:494-497.

6 Shaw GB: The Doctor's Dilemma, preface. 1913 (reprinted in Baltimore, Penguin, 1941, p 28).

\section{7}

\section{Neonatal Thrombocytopenia and Platelet Transfusion - A UK Perspective}

\section{R. Carra ${ }^{a}$ A.M. Kelly ${ }^{b}$, L.M. Williamson ${ }^{c}$}

aDepartment of Haematology, Guy's and St Thomas' Hospital, King's College London, London, 'Department of Haematology and Division of Transfusion Medicine, University of Cambridge, Cambridge, and ' NHS Blood and Transplant, Watford, UK

Five percent of newborn infants admitted to UK neonatal units during a recent study developed a platelet count $<60 \times 10^{9} / \mathrm{l}$, and $60 \%$ of these were transfused platelets. This review summarises the common causes and mechanisms of thrombocytopenia in the newborn. Relevant evidence relating the platelet count to the risk of haemorrhage is reviewed, and current UK guidance on transfusion thresholds outlined. The UK policy for the provision of platelets for transfusion to neonates is described, including the particular requirements for neonatal allo-immune thrombocytopenia. Finally, we look towards the future and prospects for reducing the need to expose newborns to donor-derived platelets.

The complete review will be published in Neonatology, vol. 107, no. $1,2015$.

\section{8}

Evidence-Based Advances in Transfusion Practice in Neonatal Intensive Care Units

R.D. Christensen ${ }^{a}$, P.D. Carroll ${ }^{a}$, C.D. Josephson ${ }^{b, c}$

aWomen and Newborns Program, Intermountain Healthcare, Salt Lake City, Utah, and ${ }^{\mathrm{b}}$ Center for Transfusion and Cellular Therapies, Emory University School of Medicine, and 'Aflac Cancer Center and Blood Disorders Services, Children's Healthcare of Atlanta, Atlanta, Ga., USA

See review, pp. 245-253. 